\title{
Assessing the evidence on the differential impact of menthol versus non- menthol cigarette use on smoking cessation: A systematic review
}

\author{
Mimi Kim ( $\nabla$ kimm1@rirt.com ) \\ RAIS https://orcid.org/0000-0002-1352-9670 \\ Geoffrey Curtin \\ RAIS
}

\author{
Research \\ Keywords: smoking, menthol cigarettes, systematic reviews, meta-analysis, smoking cessation \\ Posted Date: August 18th, 2020 \\ DOI: https://doi.org/10.21203/rs.3.rs-52105/v1 \\ License: (c) (1) This work is licensed under a Creative Commons Attribution 4.0 International License. Read Full License
}




\section{Abstract}

Background: This systematic review followed PRISMA guidelines to examine the Key Question: Does menthol cigarette use have a differential impact on smoking cessation compared with non-menthol cigarette use?

Methods: The original protocol was registered on March 22, 2016 (updated January 10, 2019; PROSPERO: CRD42019119301). Six databases were queried from inception to December 14, 2018.

Results: Fifty-seven studies (27 rated "good", 27 rated as "fair", and three studies rated as "poor" individual study quality) that compared menthol and nonmenthol smokers were qualitatively synthesized across the following cessation measures (total adjusted studies; strength of evidence grade): duration of abstinence (2; low); quit attempts (14; insufficient); rate of abstinence/quitting (28; moderate); change in smoking quantity/frequency (3; insufficient); and return to smoking/relapse (2; insufficient). Overall, the qualitative synthesis failed to show a consistent trend for the association of menthol cigarette use and smoking cessation across the outcomes. Further, meta-analytic results found no difference between menthol and non-menthol cigarette use and the two measures of quit attempts and duration of abstinence.

Implications: The overall strength of evidence for an association between menthol cigarette use and smoking cessation was graded as "low", based on deficiencies of indirectness and inconsistency in the available body of evidence. Therefore, there is no consistent, significant, or differential association between menthol cigarette use and smoking cessation.

\section{Background}

Several literature reviews examining the potential association between menthol cigarette use and smoking behaviors have been conducted (1-3); however, review methods, included studies, and overall findings and conclusions have been inconsistent. Some of the discord may reflect the complicated constructs related to smoking behaviors and the varying measurements across studies $(4,5)$.

A recent meta-analysis examined the association between menthol cigarette use and the likelihood of smoking cessation (6). The study concluded that among Blacks/African Americans in the U.S. (one sample including respondents from Canada and the U.S.), menthol smokers had approximately 12 percent lower odds of smoking cessation compared to non-menthol smokers. However, the meta-analysis from Smith et al. was not based on a full systematic review of the available evidence and, therefore, did not provide a comprehensive or clear synthesis of the available evidence.

The purpose of this systematic review was to assess the potential association between menthol cigarette use and smoking cessation, with attention paid to the measures and methods used by the included studies.

\section{Materials And Methods}

\section{Overview}

The methods used for this review were applied to a larger systematic review of the association between menthol cigarette use and three smoking behaviors (Figure 1). Current results assess the Key Question (KQ), "Does menthol cigarette use have a differential impact on smoking cessation compared to non-menthol cigarette use?" The protocol for this systematic review was registered with the PROSPERO international prospective register of systematic reviews on March 22, 2016 and updated on January 10, 2019. The record is available at:

ttps://www.crd.york.ac.uk/prospero/display_record.php?RecordID=119301.

The literature search identified 851 potentially relevant articles across sources with 838 articles from online databases and 13 additional articles through other sources. After independent review of titles and abstracts by two members of the research team, 428 references were excluded, resulting in 423 articles being screened at the full-text level (provided in SUPPLEMENTAL SECTION 1: References Included for Full-Text Review (n=423)). An additional 305 articles were excluded at the full-text level (provided in SUPPLEMENTAL SECTION 2: Excluded Studies Table (studies excluded at level 2 with reason for exclusion)), resulting in 118 relevant articles eligible for inclusion (provided in SUPPLEMENTAL SECTION 3: Included Studies List (n=118)). The weighted overall kappa for inter-rated reliability at level 2 screening was 0.96 . Fifty-seven studies (seven of which were reported in paired studies) evaluated the association between menthol cigarette smoking and smoking cessation.

\section{Conceptual Framework}

Smoking behaviors can vary across different population subgroups, suggesting that both individual and environmental factors influence smoking (7, 8). This review applied the Socio-Ecological Model created by McLeroy et al. (9) to guide consideration of the interrelationships between individuals and their social (micro-), physical (meso-), and policy (macro-) environments. This framework guided the sensitive analyses and further details on the conceptual framework are provided in SUPPLEMENTAL SECTION 4: Conceptual Framework.

\section{Literature Search Methods}

The search strategy included sources of published, peer-reviewed literature, theses and dissertations, and government and industry documents. The complete list of databases and search terms is provided in SUPPLEMENTAL SECTION 5: Search Strategy Overview. 
Detailed descriptions of terminology used to organize and synthesize this review are provided in SUPPLEMENTAL SECTION 6: Terminology.

\section{Inclusion and Exclusion Criteria}

Inclusion and exclusion criteria were developed with review and input from external subject matter experts in tobacco research and systematic reviews. Reasons for exclusion of individual studies are provided in full in SUPPLEMENTAL SECTION 7: Inclusion/Exclusion.

\section{Outcomes and Related Psychometrics}

Included studies reported on at least one of the following outcomes: duration of abstinence, quit attempts (any quit attempts; number of quit attempts per person), rate of abstinence/quitting, change in smoking quantity/frequency, and return to smoking/relapse. Recognizing that not all the outcome measures are likely to be equally valid and reliable, this review examined the following Contextual Question (CQ) to provide additional information and context for the results, "Have measures used to examine cigarette smoking cessation been psychometrically assessed as valid and reliable?" Further details are provided in SUPPLEMENTAL SECTION 8: Contextual Question.

\section{Study Designs}

Complete study and sample characteristics are provided in the Evidence Tables in SUPPLEMENTAL SECTION 9: Study, Data Set, and Sample Characteristics and SUPPLEMENTAL SECTION 10: Evidence Tables, Sample Characteristics (Unadjusted [Table 10-1 and Table 10-2] and Adjusted [Table 10-3 and Table 10-4]).

\section{ASSESSMENT OF INDIVIDUAL STUDY METHODOLOGY}

\section{Quality Assessment}

The quality of the studies included in this systematic review was assessed at the study level using the Downs and Black checklist (10), as recommended by the Cochrane Collaboration (11) and provided in Table 12-1. Further details on the Downs and Black checklist and study quality are provided in SUPPLEMENTAL SECTION 11: Study Quality Assessments and SUPPLEMENTAL SECTION 12: Additional Study Quality Methods.

\section{Evidence Synthesis}

The strongest evidence to assess whether menthol cigarette use has a differential impact on smoking cessation compared to non-menthol cigarette use would be expected to be provided by longitudinal analyses that adjusted or controlled for key confounding factors - age, race/ethnicity, and gender - by inclusion criteria, modeling, or stratification. Longitudinal analytic results were considered the highest available evidence and, as such, were weighed more heavily in the strength of evidence analysis and qualitative synthesis below. In the absence of longitudinal analytic results, the highest level of available evidence was synthesized according to studies that controlled for the predefined demographic factors.

\section{STRENGTH OF EVIDENCE EVALUATION}

The overall strength of the body of evidence was assessed and graded as "high," "moderate," "low," or "insufficient" using the Evidence-Based Practice Center (EPC) approach. Full details are provided in SUPPLEMENTAL SECTION 13: Strength of Evidence.

\section{RESULTS: SMOKING CESSATION OR QUITTING BEHAVIORS}

A total of 57 studies, reported in 64 unique references, evaluated the potential association between menthol cigarette use and smoking cessation. Table 1 below presents the five specific outcome measures for smoking cessation reported across adjusted and unadjusted studies; however, adjusted studies are considered a higher level of evidence in this synthesis. An overview of the psychometric findings for the measures of smoking cessation is presented in Table 8-1. A CQ evidence table, including reliability and validity data identified for each of the smoking-related outcome measures, is provided in Table 8-2.

Empirical data regarding reliability or validity qualified four of the five smoking cessation measures (duration of abstinence, quit attempts, rate of abstinence/quitting, change in smoking quantity/frequency) as "Acceptable." Further detail on the non-systematic literature synthesis for psychometric assessment is provided in SUPPLEMENTAL SECTION 8: Contextual Question.

\section{Synthesis of the Best Available Evidence}

Summaries of the best available evidence - controlling for age, race/ethnicity, and gender - are presented by outcome measure below. Adjusted results by age, race/ethnicity, and gender subgroups are presented in SUPPLEMENTAL SECTION 14: Adjusted Subgroup Analyses by Outcome; unadjusted results from both the full sample and subgroups of age, race/ethnicity, and gender are presented in SUPPLEMENTAL SECTION 15: Unadjusted Results. Outcome measures are presented with a corresponding overview table for each outcome in the following order: duration of abstinence; quit attempts; rate of abstinence/quitting; change in smoking quantity/frequency; and return to smoking/relapse. Where two references reported the same data, the most recent publication was used as the data source. 
Two studies, presented in Table 2, reported duration of abstinence.

Levy at al. (19) reported statistically significant lower odds of being a "recent" and "long-term" quitter for menthol compared with non-menthol smoking, across all models (AORs ranged from 0.92 to 0.97 across models). Cubbin et al. (20) reported duration of abstinence for six gender-race/ethnicity interactions, yielding only one significant finding that suggests that White female menthol smokers had been abstinent statistically significantly longer than White female non-menthol smokers (14.8 years vs. 12.5 years; $p<0.01$ ). Given the limited number of studies and the inconsistent findings reported for this measure, an association between menthol cigarette use and duration of abstinence is unclear and undefined in the evidence base.

\section{Quit Attempts (Any quit attempts; Number of quit attempts per person).}

Fourteen studies, as presented in Table 3, reported measures of quit attempts.

Kahende at al. (34) reported White menthol smokers had statistically significant lower odds than White non-menthol smokers of having made a past-year quit attempt (AOR=0.91, 95\% Cl: 0.84 to $0.99 ; p<0.05)$.

Nine studies found no difference between menthol and non-menthol smokers in terms of having made at least one quit attempt (within various timeframes), across all models and subgroup analyses/stratifications performed $(14,20,31,35-37,40,41,46)$. In addition, Stahre et al. (32) found no significant difference in the odds of using any type of quit aid between menthol and non-menthol current smokers, and menthol and non-menthol former smokers.

Three studies reported mixed findings. Levy et al. (19) reported that menthol users had statistically significant higher odds of past-year quit attempts than non-menthol users (AOR=1.03, 95\% Cl: 1.02 to $1.03 ; p<0.001)$; this result remained unchanged when adding nicotine dependence to the model. However, a third model (adjusting for additional, unspecified covariates) reported statistically significant lower odds of past year quit attempts among menthol users (AOR=0.98, 95\% Cl: 0.98 to 0.98). In Keeler et al. (29), the overall odds of past-year quit attempts between menthol and non-menthol smokers were no different. Both the 2017 and 2018 studies by Keeler at al. $(29,30)$ found Black menthol smokers were statistically significantly more likely to report pastyear quit attempts than Black non-menthol smokers (2018: $\mathrm{AOR}=1.39,95 \% \mathrm{Cl}: 1.16$ to $1.67 ; \mathrm{p}<0.001 ; 2017: \mathrm{AOR}=1.37,95 \% \mathrm{Cl}: 1.16$ to $1.61 ; \mathrm{p}=0.0002$ ); however, no such differences were reported for other racial/ethnic subgroups.

The majority of the results from these fourteen studies reported no differences between menthol and non-menthol smoking in terms of quit attempts.

\section{Rate of abstinence/quitting_(including but not limited to prolonged abstinence [PA], point prevalence abstinence [PPA], identifiable cigarette type [menthol versus non-menthol] smoked before quitting, and being a former smoker [versus current smoker]).}

Twenty-eight studies (from 31 references), presented below in Table 4, reported on rate of abstinence/quitting outcomes.

Four studies found that menthol smokers had statistically significantly lower odds of quitting than non-menthol smokers: two studies reported 7-day PPA (between weeks 14 and 26 (62); and at the previous 7 days and at week 7 (27)). Additionally, two studies examined cessation at different time points (one year abstinence from purchasing a pack of cigarettes (53); and abstinence at three to six week follow-up (43)).

Fifteen studies (from 16 references) found no difference in the rate of abstinence between menthol and non-menthol smokers, both overall and within subgroup analyses, in terms of: 7-day PPA in six studies (23, 24, 63-66); 30-day PPA in one study (42); quit rates from baseline to follow-up in three studies from four references $(41,46,50,61)$; cessation of greater than 3 months in two studies $(29,30)$; PA in two studies $(69,70)$; and, past-year abstinence in one study (55).

Nine studies (from 11 references), reported mixed significance (47, 49, 52, 54, 56-59, 68, 71, 75). Using NHIS data, Sulsky et al. (54) found that White menthol and non-menthol regular and daily smokers were no different in odds of past-year abstinence; similar results were observed in Black menthol and non-menthol daily smokers. Using TUS-CPS data, the authors found no significant difference in one- to three-year abstinence between White menthol and non-menthol smokers (both regular and daily). For other race/ethnicities, no difference was detected between menthol and non-menthol use in terms of abstinence among regular and daily smokers. However, for Black daily ( $\mathrm{AOR}=0.89,95 \% \mathrm{Cl}: 0.81$ to 0.98$)$ and regular ( $\mathrm{AOR}=0.87,95 \% \mathrm{Cl}: 0.80$ to 0.95$)$ smokers, menthol use was statistically significantly associated with lower odds of abstinence.

Reitzel et al. (68) found that menthol and non-menthol smokers were no different in terms of short-term abstinence for the overall sample. However, among White participants, menthol use predicted a statistically significant decrease in short-term abstinence $(\beta=-1.56, S E=0.79 ; \chi 2=3.96 ; p=0.05)$ as well as 7-day PPA $(\beta=-1.60, S E=0.79 ; \chi 2(1)=4.06 ; p=.04 ; n=132)$. No such differences were reported for either outcome among Black participants (shortterm abstinence: $\beta=0.54, S E=0.55 ; p=0.33$; and 7-day $P P A: \beta=1.00, S E=0.67 ; p=0.11$ ).

Blot et al. (56) found that White menthol smokers had statistically significant greater odds of having quit compared with non-menthol smokers (AOR=1.55, 95\% Cl: 1.41 to 1.70$)$; however, Black menthol and non-menthol smokers were no different.

Trinidad et al. (52) reported that, among White, Black, Asian-American/Pacific Islander, and Hispanic participants, menthol smoking was associated with statistically significant lower odds of abstinence greater than 6 months (AORs ranged from 0.28 to 0.48 ). However, among Native American/Alaskan native participants, menthol and non-menthol smokers were no different in terms of the odds of abstinence greater than 6 months. 
Delnevo et al. $(57,58)$ reported on the odds of being a former smoker across five racial/ethnic subgroups and the following five sample restrictions (according to past and current smoking status): Former smokers who quit within the past 5 years and all current smokers (regardless of quit attempt history); former smokers who quit within the past 5 years and all current smokers (regardless of quit attempt history), both of whom currently do not use other tobacco products; former smokers who quit within the past 5 years and current smokers who reported ever having made a quit attempt; former smokers who quit within the past 5 years and current smokers who reported ever having made a quit attempt, both of whom currently do not use other tobacco products; and, past 12-month cigarette smokers who made a quit attempt or quit (i.e., former smokers). Among the overall sample, across four of the five restrictions, menthol cigarette smokers were statistically significantly less likely than non-menthol smokers to be former smokers with AORs ranging from 0.90 to 0.92 .

Black menthol smokers were statistically significantly less likely to be former smokers compared to Black non-menthol smokers in all five restrictions with AORs ranging from 0.68 to 0.81 . White menthol, versus non-menthol, smokers were statistically significantly less likely to be a former smoker across three restrictions. However, Hispanic menthol and non-menthol smokers were no different across four of the five restrictions; and, were statistically significantly less likely to be a former smoker in one restriction.

In Reitzel's 'Project Mom' (71, 75), menthol cigarette use did not predict continuous abstinence from smoking. However, among White women, menthol smokers were statistically significantly less likely to maintain continuous abstinence compared to non-menthol smokers (AOR=0.19, $95 \%$ Cl: 0.04 to 0.89$)$.

Gandhi et al. (47) found no difference between White menthol and non-menthol smokers in odds of abstinence at both four weeks and six months. Black menthol smokers had statistically significant lower odds of abstinence compared to Black non-menthol smokers at both time points, four weeks (measured by 7-day PPA) (AOR=0.32, 95\% Cl: 0.16 to 0.62 ) and at 6 months post-quit (AOR=0.48, 95\% $\mathrm{Cl}: 0.25$ to 0.90$)$. Hispanic menthol smokers had statistically significant lower odds of abstinence at four weeks compared to Hispanic non-menthol smokers (AOR=0.43, $95 \% \mathrm{Cl}: 0.1$ to 0.9$)$; at six months, Hispanic menthol and non-menthol smokers were no different in odds of abstinence.

Gundersen et al. (59) suggested no significant difference in being a former smoker between menthol and non-menthol smokers in the overall sample, nor among Black smokers. However, odds of being a former smoker were statistically significantly higher for White menthol compared to White non-menthol smokers (AOR=1.17, 95\% Cl: 1.00 to $1.36 ; p<0.05)$. Odds of being a former smoker were statistically significantly lower for Hispanic menthol compared to Hispanic non-menthol smokers ( $\mathrm{AOR}=0.61,95 \% \mathrm{Cl}$ : 0.39 to $0.97 ; \mathrm{p}=0.04)$, and for non-White menthol compared to non-White non-menthol smokers $(\mathrm{AOR}=0.55,95 \% \mathrm{Cl}: 0.43$ to $0.71 ; \mathrm{p}<0.01)$.

Okuyemi et al. (49) reported no significant difference in odds of quitting between menthol and non-menthol smokers among adults $\geq 50$ years of age; however, in adults $<50$ years of age, the odds of quitting for menthol smokers were statistically significantly lower for menthol smokers $(A O R=2.02,95 \%$ Cl: 1.03 to 3.95$)$.

Across the 28 studies, the majority of studies (15 studies) found no difference between menthol and non-menthol smokers in the rate of abstinence. Four studies reported that menthol smokers were statistically significantly less likely to quit smoking and nine studies reported results of mixed significance based on various stratifications. Overall, the evidence for this outcome was inconsistent for the association between menthol cigarette use and the rate of abstinence/quitting.

\section{Change in Smoking Quantity/Frequency.}

Two studies (from four references), presented in Table 5, provided adjusted analysis of change in smoking

quantity/frequency.

One study, from two references $(46,50)$ reported no difference between menthol and non-menthol cigarette users for changes in smoking frequency. One study (from two references) reported mixed significance. Reitzel et al. $(71,75)$ found that Black female menthol, versus non-menthol, smokers reported substantially less cigarette reduction (measured by CPD) over the course of $26(\beta=3.82, S E=3.77 ; p=0.02 ; n=71)$. But no difference was found in changes in smoking frequency for the overall sample.

The overall evidence base for this outcome was limited by the small number of included studies, and the mixed significance of findings across studies precludes clear conclusions from the available evidence.

\section{Return to Smoking/Relapse}

Two studies, presented in Table 6, provided analyses of return to smoking/relapse.

In Muench and Juliano (74), menthol smokers were at a statistically significant greater risk of lapsing compared with non-menthol smokers, in both the univariate regression $(A O R=3.474, p<0.05)$ and lapse survival curve analyses $(H R=2.798$, Wald statistic=2.79; $p=0.048)$. Pletcher et al. $(41)$, reported that young adult menthol smokers had a statistically significant higher likelihood of returning to smoking, compared to non-menthol smokers (AOR=1.89, $95 \%$ Cl: 1.17 to $3.05 ; p=0.009)$.

The results from the two included studies suggest a higher likelihood of menthol smokers returning to smoking. However, the small number of studiesneither of which is based on a nationally representative sample-limit the generalizability of the association between menthol cigarette use and returning 
to smoking/relapse.

\section{SENSITIVITY ANALYSES (ADJUSTED RESULTS)}

Three sensitivity analyses were conducted in order to test whether the results differed after more stringent inclusion and exclusion criteria were applied. Overall, results from the sensitivity analyses suggested little to no change. Full details on the sub-group analysis and sensitivity analyses are provided in SUPPLEMENTAL SECTION 16: Sensitivity Analyses (Adjusted Results).

\section{RESULTS OF META-ANALYSIS}

All studies considered for meta-analyses controlled, at minimum, for age, gender, race/ethnicity. Menthol cigarette use was defined as either self-reported menthol use, current use, usual cigarette/brand used, or remaining with menthol cigarettes through the length of the study. Subgroup analyses were conducted to compare differences between study designs (prospective cohort and cross-sectional designs in abstinence [no duration]) and differences in measures (past year and ever quit attempt [ever quit attempts, any quit attempts between 2001 and 2005, and any quit attempts in the past 2, 3, or 5 years]). Further, sensitivity analyses were also completed according to race/ethnicity and abstinence verification (eCO verified), when possible. Pooled adjusted odds ratios (AORs) and 95\% confidence intervals (Cls) with two-sided $\mathrm{P}$ values are reported from random-effects models utilizing the DerSimonian and Laird method (76) to measure the likelihood of reporting quit attempts and abstaining among menthol compared to non-menthol smokers. Pooled data for the meta-analyses were extracted for two outcome measures: quit attempts and duration of abstinence.

After screening all included adjusted studies, nine studies were included in the meta-analyses for quit attempts $(14,19,29,31,34-36,41,46)$ and 12 studies for abstinence $(23,24,27,41,47,49,56,57,59,62,64,66)$. Full details are provided in SUPPLEMENTAL SECTION 17: Characteristics, Definitions, and Covariates of Studies Included in the Meta-Analysis and SUPPLEMENTAL SECTION 18: Forest Plots of Meta-Analyses.

\section{Adjusted Odds of Reporting a Quit Attempt (Past Year or Ever).}

Results from five studies (Figure 18-1) were pooled to measure the association of menthol use and past year quit attempts. Pooled results showed a statistically significant association between menthol, versus non-menthol, cigarette use and the increasing odds for past year quit attempts (OR=1.02, $95 \% \mathrm{Cl}: 1.01$ to 1.03 , p-value=0.003, $\mathrm{l}^{2}=1 \%$ ). However, the pooled result (Figure 18-2) from studies measuring ever quit attempts, any quit attempts between 2001 to 2005, and any quit attempt in the past 2, 3, or 5 years found no significant difference in the odds of making a quit attempt when comparing menthol and non-menthol smokers ( $\mathrm{OR}=0.93,95 \% \mathrm{Cl}, 0.82$ to $\left.1.05, \mathrm{p}=0.23, \mathrm{I}^{2}=0 \%\right)(14,41,46)$. Results from two studies were pooled to measure for the association of menthol cigarette use and quit attempts (past year and quit attempts between 2001 and 2005 ) among Black participants $(29,46)$. Pooled results (Figure 18-4) showed a significant increase in the odds of Black menthol, versus non-menthol, smokers reporting quit attempts $\left(\mathrm{OR}=1.37,95 \% \mathrm{Cl}: 1.17\right.$ to $\left.1.61, \mathrm{p}=0.00001, \mathrm{l}^{2}=14 \%\right)$. In contrast, among White menthol respondents in three studies (Figure 18-5), the odds of making a quit attempt were statistically significantly lower for menthol compared to non-menthol smokers $\left(\mathrm{OR}=0.95,95 \% \mathrm{Cl}: 0.91\right.$ to $\left.0.99, \mathrm{I}^{2}=0 \%\right)(29,34,46)$.

\section{Adjusted Odds of Abstinence (No definition and 7-day PPA)}

Data from four studies were pooled to measure the association of menthol use and abstinence (self-reported) with no specified duration of abstinence $(41,56,57,59)$. Recognizing the high heterogeneity balanced by the narrow confidence intervals, the pooled results showed no difference between menthol and non-menthol smokers in the odds of abstinence with no defined duration (Figure 18-6) $\left(0 \mathrm{R}=0.96,95 \% \mathrm{Cl}: 0.84\right.$ to $\left.1.10, \mathrm{p}=0.58, \mathrm{I}^{2}=71 \%\right)$.

Pooled data from three studies measuring the association of menthol use and abstinence with no specified duration of abstinence for Black and White menthol and non-menthol smokers were no different in terms of abstinence $(56,57,59)$ (Figures $18-7$ and $18-8)(O R=0.90,95 \% \mathrm{Cl}$ : 0.73 to $1.10, p=0.29$, $\mathrm{I}^{2}=73 \%$ ). Again, the heterogeneity was noted to be high. Individual meta-analysis results from four cohort studies measuring the association of menthol use and smoking abstinence measured by 7-day PPA are presented in Figure 18-9. When pooling results across these four studies, Black menthol smokers had statistically significantly lower odds of smoking abstinence 7-day PPA (OR=0.52, 95\% Cl: 0.38 to $\left.0.70, p<0.0001, \mathrm{I}^{2}=0 \%\right)($ Figure $18-10)(24,27,47,49)$. These pooled results suggest an unclear association between cigarette type and abstinence. This may be due to the high heterogeneity among studies measuring this association, even when stratifying by study design and abstinence measures with specified duration.

\section{STRENGTH OF EVIDENCE}

Table 7a provides the SOE for the outcomes used in the current review to examine the association between menthol cigarette use and cessation outcomes. The adjusted data, treated as the higher level of evidence, were the primary source of data for this evidence synthesis and meta-analyses. Most measures were "indirect" and limited by the varying and/or undefined measures of abstinence. As presented in Table 7b, the overall strength of evidence for an association between menthol cigarette use and smoking cessation was graded as "low" based on deficiencies in the available evidence base.

\section{Limitations}

This systematic review was conducted according to established methodological standards and with inherent limitations. For example, the variation in the definitions of several outcome measures made it challenging to summarize results, which limited the reviewers' ability to draw confident conclusions. Most of the smoking behavior data were self-reported. However, any differential impact of reliance on self-reported data was expected to be minimal. The Downs and Black checklist has some limitations when applied across a variety of study designs. Furthermore, a study's quality score on the Downs and 
Black checklist may reflect the quality of reporting rather than the quality of the study as conducted. Finally, the conclusions in this review are based on studies conducted in the U.S. and may or may not be generalizable to other countries due to the potential impact of important influences, such as cultural norms, smoking policies, and taxes on smoking behaviors outside of the U.S.

\section{Discussion And Conclusions}

Studies in the qualitative synthesis of this review were considered as providing the best available evidence on the differential impact of menthol versus non-menthol cigarette use on smoking cessation. Across studies, a variety of sampling and recruitment methods were used with varying definitions of current smoking and abstinence, and a range of study designs that, in many instances, did not directly address the current research question. Further, the available studies provided evidence that was inconsistent and imprecise-both across studies and within the same study.

Analyses of large cross-sectional studies yielded inconsistent findings. Among studies that used data from nationally representative samples, TUS-CPS and NHIS, population and sub-population results were mixed, based on modeling variation or definitions used; specifically, statistically significantly positive and negative associations between menthol cigarette use and smoking cessation were reported, as well as numerous non-significant findings.

Clinical trials are designed to assess associations between interventions and outcomes, providing the temporal component that cross-sectional data lack. No clinical trials included this review were designed with menthol as the "intervention" to which participants were assigned. Therefore, these studies were re-classified as short-term prospective cohort studies. There was no consistent pattern of a differential impact of menthol versus non-menthol cigarette use on smoking cessation, even when data were stratified by type of cessation intervention, duration of intervention and follow up, or definition of outcome (including biochemical validation of self-reported abstinence). Both the shortest ( 6 weeks) and the longest (12 months) clinical studies found mixed or equivalent results. In addition, trials of cessation inherently include self-selected participants at least interested or motivated to quit smoking. Relying solely-or mainly-on clinical trial data to draw conclusions about the association between menthol cigarette use and smoking cessation will yield a result with limited generalizability to the overall smoking population.

The included prospective studies varied in follow-up duration - a critical factor in assessing the durability of cessation. Of the ten prospective cohort studies that reported cessation, eight reported outcomes at six months or longer post-baseline. Specifically, three reported outcomes at six to twelve months, one followed participants for three to five years, and four assessed outcomes beyond five years post-baseline. Two of the three 6- to 12-month cohort studies included a cessation intervention of some form - 7-day and 30-day PPA. The third 6- to 12-month cohort study reported continuous abstinence.

In the longer-term cohort studies, results were of mixed significance. COMMIT (a community-based public health intervention conducted in 11 matched pairs of communities) assessed menthol smoking at baseline in 1988; participants were interviewed again in 1993, 1998, 2001, and 2005. Investigators found no difference between menthol, versus non-menthol, smokers and smoking cessation during 17 years of follow up. The CARDIA study, a cohort of young adults at baseline, found no association between menthol cigarette use and cessation at 15-year follow up. However, a statistically significant positive association between menthol cigarette use and the risk of smoking relapse was identified. Finally, a study that investigated the association between menthol smoking and quit rate found that menthol smokers had a statistically significant lower likelihood of quitting compared with non-menthol smokers.

Return to smoking/relapse and change in smoking quantity/frequency were each reported by only two studies, even with consideration of unadjusted results. Data were too limited to draw a reliable conclusion about the association between menthol cigarette use and either measure. Quit attempts making at least one attempt and the number of quit attempts per person - were reported by several studies, but the measure does not reflect actual cessation. Given the lack of a significant difference between menthol and non-menthol smokers on either measure of quit attempts and the empirical uncertainty of the association between making a quit attempt or the number of quit attempts and actual cessation, there is no confident conclusion that can be drawn regarding an association with menthol smoking.

Pooled data for the meta-analyses were extracted for two outcome measures: quit attempts and abstinence. Pooled results from five studies suggested a statistically significant association between menthol cigarette use and increased odds for past year quit attempts. However, pooled data from three studies measuring ever quit attempts found no difference between menthol and non-menthol smokers in the odds of making a quit attempt. Pooling data from all eight studies revealed no consistent differences.

Additional analysis of pooled data from two studies presenting results on quit attempts among Black participants showed a statistically significant increase in odds for that Black menthol, versus non-menthol, smokers were statistically significantly more likely to make a quit attempt. Further, pooled data from three studies suggested that White menthol, versus non-menthol, smokers were statistically significantly less likely of making a quit attempt.

Four cohort studies presented results for examining the association between menthol use and abstinence, with no specified duration. Pooled results showed no difference between menthol and non-menthol smokers in terms of abstinence, even in sub-analyses of Black and White participants, using data from three of the four studies.

Across all four cohort studies, pooled results on the association between menthol use and abstinence, again with no specified duration, showed no difference between menthol and non-menthol smokers, overall, in the odds of abstinence. However, when measuring abstinence by 7-day PPA, pooled data suggest that Black menthol smokers were statistically significantly less likely than Black non-menthol smokers to be abstinent. Recognizing inconsistent results were reported across studies in the qualitative synthesis, meta-analytic results, generally, showed no difference between menthol 
cigarette use and quit attempts (pooled results from ever, past year quit attempts, any quit attempts between 2001 to 2005 , and any quit attempt in the past 2, 3, or 5 years), abstinence with no defined duration, and 7-day PPA.

The above conclusions contradict several existing literature reviews on this topic. The 2013/2015 FDA Report/Addendum (2, 3) concluded that menthol in cigarettes was "likely associated with reduced success in smoking cessation, especially among Black menthol smokers." That finding was not supported

by this newer, more comprehensive review. Similarly, the evidence that contributed to this review does not support the conclusion in the 2011 Report by the FDA's Tobacco Products Scientific Advisory Committee (1) that "[elvidence is sufficient to conclude that a relationship is more likely than not that the availability of menthol cigarettes results in lower likelihood of smoking cessation in Blacks."

In summary, this review included nearly three times the number of studies as the 2013 FDA Report and 2015 Addendum, including 16 studies that analyzed data among Black smokers only, and the evidence is not strong or consistent enough to support a clear association-positive or negativebetween menthol cigarette use and smoking cessation. Four of this review's 16 studies that reported rates of abstinence/quitting among Black smokers reported that Black menthol smokers were statistically significantly less likely to become abstinent, compared with Black non-menthol smokers. However, ten studies found no difference between Black menthol and non-menthol cigarette smokers in terms of cessation, and two studies reported mixed or unclear results. Given the heterogeneity of study designs, applied measures, and the low strength of evidence, the available literature does not demonstrate a clear and confident differential association between menthol, versus non-menthol, cigarette use and smoking cessation.

\section{Declarations}

AUTHORS' CONTRIBUTIONS: M.K. and G.M. co-lead the conceptualization of this review and served as subject matter experts throughout the review process. M.K. led the preparation and finalization of the manuscript. G.C. served as the second author for all aspects of the manuscript preparation process including critically revising the manuscript and reviewing accuracy of all technical details. The corresponding author attests that the listed authors meet authorship criteria and that no others meeting the criteria have been omitted.

FUNDING: All study activities were executed by providers external to RAI Services Company (Venebio and Thera-Business). These providers were financially compensated for services according to contractual terms with RAI Services Company. RAI Services Company is a wholly owned subsidiary of Reynolds American Inc., whose operating companies manufacture and market tobacco products. Reynolds American Inc. was acquired by British American Tobacco in July 2017. Both Drs. Kim and Curtin serve as full-time employees of RAI Services Company.

COMPETING INTERESTS: Both Drs. Kim and Curtin serve as full-time employees of RAI Services Company, a wholly owned subsidiary of Reynolds American Inc., a manufacturer and marketer of tobacco products.

ETHICS STATEMENT: Ethical approval for this study was not required.

CONSENT FOR PUBLICATION: Not required for this publication as no individual or identifiable information is considered.

AVAILABLITY OF DATA AND MATERIALS: All data and materials considered in this review are publicly available.

ACKNOWLEDGEMENTS: The authors would like to acknowledge the Venebio Group, LLC (Richmond, VA) for providing their systematic review expertise to execute the original synthesis of the evidence base and all study activities across all levels of the review process. The authors also acknowledge TheraBusiness (Ontario CANADA) for providing their systematic review expertise to all study activities across all levels of the updated review process.

\section{Abbreviations}




\begin{tabular}{|c|c|}
\hline Abbreviation & Definition \\
\hline AOR & adjusted odds ratio \\
\hline BRFSS & Behavioral Risk Factor Surveillance System \\
\hline CARDIA & Coronary Artery Risk Development in Young Adults \\
\hline $\mathrm{Cl}$ & confidence interval \\
\hline COMMIT & Community Intervention Trial for Smoking Cessation \\
\hline CPD & cigarettes per day \\
\hline CQ & Contextual Question \\
\hline EPC & Evidence-Based Practice Center \\
\hline HR & hazard ratio \\
\hline ITC-4 & International Tobacco Control Four Country Survey \\
\hline KIS & Kick it at Swope \\
\hline KQ & Key Question \\
\hline LYAC & Legacy Young Adult Cohort Study \\
\hline NA & Not Applicable \\
\hline NHIS & National Health Interview Survey \\
\hline NHIS-CCS & National Health Interview Survey Cancer Control Supplement \\
\hline PA & prolonged abstinence \\
\hline POR & prevalence odds ratio \\
\hline PPA & point (or period) prevalence abstinence \\
\hline PR & prevalence ratio \\
\hline SE & standard error \\
\hline SOE & Strength of Evidence \\
\hline TUS-CPS & The Tobacco Use Supplement to the Current Population Survey \\
\hline U.S. & United States \\
\hline WSHS & Wisconsin Smokers Health Study \\
\hline
\end{tabular}

\section{References}

1. Alexander LA, Crawford T, Mendiondo MS. Occupational status, work-site cessation programs and policies and menthol smoking on quitting behaviors of US smokers. Addiction. 2010;105(Suppl 1):95-104.

2. Berg CJ, Thomas JL, Guo H, An LC, Okuyemi KS, Collins TC, Ahluwalia JS. Predictors of smoking reduction among Blacks. Nicotine Tob Res. 2010;12(4):423-31.

3. Blot WJ, Cohen SS, Aldrich M, McLaughlin JK, Hargreaves MK, Signorello LB. Lung cancer risk among smokers of menthol cigarettes. J Natl Cancer Inst. 2011;103(10):810-6.

4. Brooks DR, Palmer JR, Strom BL, Rosenberg L. 2003. Menthol cigarettes and risk of lung cancer. Am J Epidemiol 158(7), 609-616; discussion 617620.

5. Cropsey KL, Weaver MF, Eldridge GD, Villalobos GC, Best AM, Stitzer ML. Differential success rates in racial groups: results of a clinical trial of smoking cessation among female prisoners. Nicotine Tob Res. 2009;11(6):690-7.

6. Cubbin C, Soobader MJ, LeClere FB. The intersection of gender and race/ethnicity in smoking behaviors among menthol and non-menthol smokers in the United States. Addiction. 2010;105(Suppl 1):32-8.

7. Cummings $P$. The relative merits of risk ratios and odds ratios. Arch Pediatr Adolesc Med. 2009;163(5):438-45.

8. D'Silva J, Boyle RG, Lien R, Rode P, Okuyemi KS. Cessation outcomes among treatment-seeking menthol and nonmenthol smokers. Am J Prev Med. 2012;43(5 Suppl 3):242-8.

9. Examining the relationship between menthol smoking and cessation using data from the 2003 and 2006/7 Tobacco Use Supplement Delnevo CD, Gundersen DA, Hrywna M. 2010. Examining the relationship between menthol smoking and cessation using data from the 2003 and 2006/7 Tobacco Use Supplement. University of Medicine \& Dentistry of New Jersey - School of Public Health, Center for Tobacco Surveillance and Evaluation Research, p. 61. 
10. Delnevo CD, Gundersen DA, Hrywna M, Echeverria SE, Steinberg MB. Smoking-cessation prevalence among U.S. smokers of menthol versus nonmenthol cigarettes. Am J Prev Med. 2011;41(4):357-65.

11. Delnevo CD, Villanti AC, Wackowski OA, Gundersen DA, Giovenco DP. 2015. The influence of menthol, e-cigarettes and other tobacco products on young adults' self-reported changes in past year smoking. Tob Control.

12. Downs SH, Black N. The feasibility of creating a checklist for the assessment of the methodological quality both of randomised and non-randomised studies of health care interventions. J Epidemiol Community Health. 1998;52(6):377-84.

13. Fagan P, Augustson E, Backinger CL, O'Connell ME, Vollinger RE Jr, Kaufman A, Gibson JT. Quit attempts and intention to quit cigarette smoking among young adults in the United States. Am J Public Health. 2007;97(8):1412-20.

14. Fagan P, Moolchan ET, Hart A Jr, Rose A, Lawrence D, Shavers VL, Gibson JT. Nicotine dependence and quitting behaviors among menthol and nonmenthol smokers with similar consumptive patterns. Addiction. 2010;105(Suppl 1):55-74.

15. Fagan P, Pohkrel P, Herzog T, Pagano I, Vallone D, Trinidad DR, Sakuma KL, Sterling K, Fryer CS, Moolchan E. Comparisons of three nicotine dependence scales in a multiethnic sample of young adult menthol and non-menthol smokers. Drug Alcohol Depend. 2015;149:203-11.

16. Faseru B, Choi WS, Krebill R, Mayo MS, Nollen NL, Okuyemi KS, Ahluwalia JS, Cox LS. Factors associated with smoking menthol cigarettes among treatment-seeking African American light smokers. Addict Behav. 2011;36(12):1321-4.

17. Faseru B, Nollen NL, Mayo MS, Krebill R, Choi WS, Benowitz NL, Tyndale RF, Okuyemi KS, Ahluwalia JS, Cox S, L. Predictors of cessation in African American light smokers enrolled in a bupropion clinical trial. Addict Behav. 2013;38(3):1796-803.

18. Foulds J, Gandhi KK, Steinberg MB, Richardson DL, Williams JM, Burke MV, Rhoads GG. Factors associated with quitting smoking at a tobacco dependence treatment clinic. Am J Health Behav. 2006;30(4):400-12.

19. Fu SS, Okuyemi KS, Partin MR, Ahluwalia JS, Nelson DB, Clothier BA, Joseph AM. Menthol cigarettes and smoking cessation during an aided quit attempt. Nicotine Tob Res. 2008;10(3):457-62.

20. Gandhi KK, Foulds J, Steinberg MB, Lu SE, Williams JM. Lower quit rates among African American and Latino menthol cigarette smokers at a tobacco treatment clinic. Int J Clin Pract. 2009;63(3):360-7.

21. Gubner NR, Williams DD, Pagano A, Campbell BK, Guydish J. Menthol cigarette smoking among individuals in treatment for substance use disorders. Addictive behaviors. 2018;80:135-41.

22. Gundersen DA, Delnevo CD, Wackowski O. Exploring the relationship between race/ethnicity, menthol smoking, and cessation, in a nationally representative sample of adults. Prev Med. 2009;49(6):553-7.

23. Harris KJ, Okuyemi KS, Catley D, Mayo MS, Ge B, Ahluwalia JS. Predictors of smoking cessation among African-Americans enrolled in a randomized controlled trial of bupropion. Prev Med. 2004;38(4):498-502.

24. Heck JD, Hamm LA, Lauterbach JH. Non-Voting Industry Representatives of the Tobacco Products Scientific Advisory Committee, March $23,2011$. The Industry Menthol Report. Menthol Cigarettes: No Disproportionate Impact on Public Health.

25. Hersey JC, Ng SW, Nonnemaker JM, Mowery P, Thomas KY, Vilsaint MC, Allen JA, Haviland ML. Are menthol cigarettes a starter product for youth? Nicotine Tob Res. 2006;8(3):403-13.

26. Higgins JPT, Altman DG, Sterne JAC. 2011. Section 13.5. Assessing risk of bias in non-randomized studies, in: Higgins, J.P.T., Green, S, editors, Cochrane Handbook for Systematic Reviews of Interventions. The Cochrane Collaboration.

27. Holm M, Schioler L, Andersson E, Forsberg B, Gislason T, Janson C, Jogi R, Schlunssen V, Svanes C, Toren K. Predictors of smoking cessation: A longitudinal study in a large cohort of smokers. Respir Med. 2017;132:164-9.

28. Hyland A, Garten S, Giovino GA, Cummings KM. Mentholated cigarettes and smoking cessation: Findings from COMMIT. Tob Control. 2002;11:135-9.

29. Hyland A, Rivard C. 2010. Analysis of mentholated cigarettes using the COMMIT data - summary. Department of Health Behavior, Roswell Park Cancer Institute.

30. Jarvik ME, Tashkin DP, Caskey NH, McCarthy WJ, Rosenblatt MR. Mentholated cigarettes decrease puff volume of smoke and increase carbon monoxide absorption. Physiol Behav. 1994;56(3):563-70.

31. Kahende JW, Malarcher AM, Teplinskaya A, Asman KJ. Quit attempt correlates among smokers by race/ethnicity. Int J Environ Res Public Health. 2011;8(10):3871-88.

32. Kandel DB, Kiros G-E, Schaffran C, Hu M-C. Racial/Ethnic Differences in Cigarette Smoking Initiation and Progression to Daily Smoking: A Multilevel Analysis. Am J Public Health. 2004;94(1):128-35.

33. Kanyuch JA, Bercz PA, Chang J, Martinez FJ, Criner GJ, Lawrence MJ, Tomko PA, Foreman MG, Silverman E, Crapo JD, Sciurba FC, Investigators C. 2011. Menthol cigarette use among African Americans associated with persistent tobacco use. Am J Respir Crit Care Med, p. A4568.

34. Kasza KA, Hyland AJ, Bansal-Travers M, Vogl LM, Chen J, Evans SE, Fong GT, Cummings KM, O'Connor RJ. Switching between menthol and nonmenthol cigarettes: findings from the U.S. Cohort of the International Tobacco Control Four Country Survey. Nicotine Tob Res. 2014;16(9):125565.

35. Keeler C, Max W, Yerger V, Yao T, Ong MK, Sung H-Y. The Association of Menthol Cigarette Use With Quit Attempts, Successful Cessation, and Intention to Quit Across Racial/Ethnic Groups in the United States. Nicotine tobacco research: official journal of the Society for Research on Nicotine Tobacco. 2017;19(12):1450-64. 
36. Keeler C, Max W, Yerger VB, Yao T, Wang Y, Ong MK, Sung H-Y. Effects of cigarette prices on intention to quit, quit attempts, and successful cessation among African American smokers. Nicotine \& tobacco research: official journal of the Society for Research on Nicotine and Tobacco; 2018.

37. King A, Cao D, Matthews A. 2011. Influence of menthol use on smoking cessation outcomes in a smoking cessation treatment program.

38. Levy DT, Blackman K, Tauras J, Chaloupka FJ, Villanti AC, Niaura RS, Vallone DM, Abrams DB. Quit attempts and quit rates among menthol and nonmenthol smokers in the United States. Am J Public Health. 2011;101(7):1241-7.

39. Lewis M, Wang Y, Berg CJ. Tobacco control environment in the United States and individual consumer characteristics in relation to continued smoking: differential responses among menthol smokers? Prev Med. 2014;65:47-51.

40. McLeroy KR, Bibeau D, Steckler A, Glanz K. An ecological perspective on health promotion programs. Health Educ Q. 1988;15(4):351-77.

41. Mendiondo MS, Alexander LA, Crawford T. Health profile differences for menthol and non-menthol smokers: findings from the National Health Interview Survey. Addiction. 2010;105(Suppl 1):124-40.

42. Miller GE, Jarvik ME, Caskey NH, Segerstrom SC, Rosenblatt MR, McCarthy WJ. Cigarette mentholation increases smokers' exhaled carbon monoxide levels. Exp Clin Psychopharm. 1994;2(2):154-60.

43. Muench C, Juliano LM. Predictors of smoking lapse during a 48-hour laboratory analogue smoking cessation attempt. Psychology of addictive behaviors: journal of the Society of Psychologists in Addictive Behaviors. 2017;31(4):415-22.

44. Murray RP, Connett JE, Skeans MA, Tashkin DP. Menthol cigarettes and health risks in Lung Health Study data. Nicotine Tob Res. 2007;9(1):101-7.

45. Muscat JE, Richie JP Jr, Stellman SD. Mentholated cigarettes and smoking habits in whites and blacks. Tob Control. 2002;11:368-71.

46. Nonnemaker J, Hersey J, Homsi G, Busey A, Allen J, Vallone D. Initiation with menthol cigarettes and youth smoking uptake. Addiction. 2012;108(1):171-8.

47. O'Connor RJ, Bansal-Travers M, Carter LP, Cummings KM. What would menthol smokers do if menthol in cigarettes were banned? Behavioral intentions and simulated demand. Addiction. 2012;107(7):1330-8.

48. Okuyemi KS, Ahluwalia JS, Ebersole-Robinson M, Catley D, Mayo MS, Resnicow K. Does menthol attenuate the effect of bupropion among African. American smokers? Addiction. 2003;98:1387-93.

49. Okuyemi KS, Ebersole-Robinson M, Nazir N, Ahluwalia JS. African-American menthol and nonmenthol smokers: Differences in smoking and cessation experiences. J Natl Med Assoc. 2004;96(9):1208-11.

50. Okuyemi KS, Faseru B, Cox S, Bronars L, Ahluwalia CA, J.S. Relationship between menthol cigarettes and smoking cessation among African American light smokers. Addiction. 2007;102(12):1979-86.

51. Park J-Y. 2017. Tobacco use behaviors among vulnerable populations. Dissertation Abstracts International: Section B: The Sciences and Engineering 77(12-B(E)), No-Specified.

52. Pearson JL. 2011. Public reaction to potential food and drug administration actions under the family smoking prevention and tobacco control act: Regulating e-cigarettes, banning menthol, and reducing cigarette nicotine content. Johns Hopkins University, p. 142.

53. Pearson JL, Abrams DB, Niaura RS, Richardson A, Vallone D. A ban on menthol cigarettes: Impact on public opinion and smokers' intention to quit. Am J Public Health. 2012;102(11):e107-14.

54. Piper ME, Cook JW, Schlam TR, Jorenby DE, Smith SS, Bolt DM, Loh WY. Gender, race, and education differences in abstinence rates among participants in two randomized smoking cessation trials. Nicotine Tob Res. 2010;12(6):647-57.

55. Pletcher MJ, Hulley BJ, Houston T, Kiefe Cl, Benowitz N, Sidney S. Menthol cigarettes, smoking cessation, atherosclerosis, and pulmonary function: the Coronary Artery Risk Development in Young Adults (CARDIA) Study. Arch Intern Med. 2006;166:1915-22.

56. Rath JM, Villanti AC, Williams VF, Richardson A, Pearson JL, Vallone DM. 2015. Patterns of Longitudinal Transitions in Menthol Use Among US Young Adult Smokers. Nicotine Tob Res 17(7), 839-846.

57. Reitzel LR. 2011a. Menthol cigarettes, tobacco dependence, and smoking cessation: Project BREAK FREE final report. The University of Texas, MD Anderson Cancer Center.

58. Reitzel LR. 2011b. Menthol cigarettes, tobacco dependence, and smoking cessation: Project CARE final report. University of Texas, MD Anderson Cancer Center.

59. Reitzel LR. 2011c. Menthol cigarettes, tobacco dependence, and smoking cessation: Project MOM final report. The University of Texas, MD Anderson Cancer Center.

60. Reitzel LR, Li Y, Stewart DW, Cao Y, Wetter DW, Waters AJ, Vidrine JI. Race moderates the effect of menthol cigarette use on short-term smoking abstinence. Nicotine Tob Res. 2013;15(5):883-9.

61. Reitzel LR, Nguyen N, Cao Y, Vidrine JI, Daza P, Mullen PD, Velasquez MM, Li Y, Cinciripini PM, Cofta-Woerpel L, Wetter DW. Race/ethnicity moderates the effect of prepartum menthol cigarette use on postpartum smoking abstinence. Nicotine Tob Res. 2011;13(12):1305-10.

62. Rojewski AM, Toll BA, O'Malley SS. Menthol cigarette use predicts treatment outcomes of weight-concerned smokers. Nicotine Tob Res. 2014;16(1):115-9.

63. Rosenbloom J, Rees VW, Reid K, Wong J, Kinnunen T. A cross-sectional study on tobacco use and dependence among women: Does menthol matter? Tob Induc Dis. 2012;10(19):1-6.

64. Sidney S, Tekawa IS, Friedman GD. Mentholated cigarette use among multiphasic examinees, 1979-86. Am J Public Health. 1989;79:1415-6. 
65. Smith PH, Assefa B, Kainth S, Salas-Ramirez KY, McKee SA, Giovino GA. 2019. Use of Mentholated Cigarettes and Likelihood of Smoking Cessation in the United States: A Meta-Analysis. Nicotine Tob Res.

66. Smith SS, Fiore MC, Baker TB. Smoking cessation in smokers who smoke menthol and non-menthol cigarettes. Addiction. 2014;109(12):2107-17.

67. Soulakova JN, Hartman AM, Liu B, Willis GB, Augustine S. Reliability of adult self-reported smoking history: data from the tobacco use supplement to the current population survey 2002-2003 cohort. Nicotine Tob Res. 2012;14(8):952-60.

68. Stahre M, Okuyemi KS, Joseph AM, Fu SS. Racial/ethnic differences in menthol cigarette smoking, population quit ratios and utilization of evidencebased tobacco cessation treatments. Addiction. 2010;105(Suppl 1):75-83.

69. Stanton CA, Papandonatos G, Lloyd-Richardson EE, Niaura R. Consistency of self-reported smoking over a 6-year interval from adolescence to young adulthood. Addiction. 2007;102(11):1831-9.

70. Steinberg MB, Bover MT, Richardson DL, Schmelzer AC, Williams JM, Foulds J. Abstinence and psychological distress in co-morbid smokers using various pharmacotherapies. Drug Alcohol Depend. 2011;114(1):77-81.

71. Sulsky SI, Fuller WG, Van Landingham C, Ogden MW, Swauger JE, Curtin GM. Evaluating the association between menthol cigarette use and the likelihood of being a former versus current smoker. Regul Toxicol Pharmacol. 2014;70(1):231-41.

72. Thihalolipavan S, Jung M, Jasek J, Chamany S. Menthol smokers in large-scale nicotine replacement therapy program. Am J Public Health. 2014;104(11):e3-4.

73. Tobacco Products Scientific Advisory Committee, 2011. Menthol Report and Recommendation. http://www.fda.gov/downloads/AdvisoryCommittees/CommitteesMeetingMaterials/TobaccoProductsScientificAdvisoryCommittee/UCM269697.pdf. (Accessed 15 August 2016).

74. Trinidad DR, Perez-Stable EJ, Messer K, White MM, Pierce JP. Menthol cigarettes and smoking cessation among racial/ethnic groups in the United States. Addiction. 2010;105(Suppl 1):84-94.

75. U.S. Food and Drug Administration, 2013. Preliminary Scientific Evaluation of the Possible Public Health Effects of Menthol Versus Nonmenthol Cigarettes. http://www.fda.gov/downloads/ScienceResearch/SpecialTopics/PeerReviewofScientificlnformationandAssessments/UCM361598.pdf. (Accessed 15 August 2016).

76. U.S. Food and Drug Administration, 2015. Reference Addendum: Preliminary Scientific Evaluation of the Possible Public Health Effects of Menthol versus Non-menthol Cigarettes.

http://www.fda.gov/downloads/ScienceResearch/SpecialTopics/PeerReviewofScientificlnformationandAssessments/UCM362600.pdf. (Accessed 24 October 2016).

77. Webb Hooper M, Zhao W, Byrne MM, Davila E, Caban-Martinez A, Dietz NA, Parker DF, Huang Y, Messiah A, Lee DJ. Menthol cigarette smoking and health, Florida 2007 BRFSS. Am J Health Behav. 2011;31(1):3-14.

78. Winhusen TM, Adinoff B, Lewis DF, Brigham GS, Gardin JG 2nd, Sonne SC, Theobald J, Ghitza U. A tale of two stimulants: mentholated cigarettes may play a role in cocaine, but not methamphetamine, dependence. Drug Alcohol Depend. 2013;133(3):845-51.

79. Yi Z, Mayorga ME, Hassmiller Lich K, Pearson JL. Changes in cigarette smoking initiation, cessation, and relapse among U.S. adults: a comparison of two longitudinal samples. Tobacco Induced Diseases. 2017;15:17.

\section{Tables}

Table 1: Outcome Measures for Smoking Cessation across Adjusted and Unadjusted Studies 


\begin{tabular}{|c|c|}
\hline Measure and definition & Studies \\
\hline \multicolumn{2}{|l|}{ Duration of abstinence } \\
\hline Longest period of abstinence in past 12 months among current smokers & $(12)$ \\
\hline Longest period of abstinence among current smokers & (13), (14), (15), (16) \\
\hline Duration of most recent quit attempt among current smokers & $(15)$ \\
\hline Percent reporting longest quit time longer than 90 days among current smokers & $(17)$ \\
\hline Quit within past year vs. at least 1 year among former smokers & $(18)$ \\
\hline Quit between 3 months and 1 year; quit between 3 months and 5 years among former smokers & (19) \\
\hline Time since quit (continuous measure) among former smokers & (20), (21), (22) \\
\hline \multicolumn{2}{|l|}{ Quit attempts (any quit attempts; number of quit attempts per person) } \\
\hline $\begin{array}{l}\text { Number of times during the past } 12 \text { months [respondent] stopped smoking for at least } 24 \text { hours } \\
\text { because [respondent was] trying to quit }\end{array}$ & (14), (12), (23), (24), (25) \\
\hline Number of times participant went at least 24 hours without smoking (no time period reported) & $(26),(27)$ \\
\hline Tried to quit smoking in the past 12 months & (28), (29), (30), (31), (32) \\
\hline $\begin{array}{l}\text { At least } 24 \text { hours without smoking in the past } 12 \text { months because [respondent was] trying to quit } \\
\text { smoking }\end{array}$ & (25), (33), (34), (19), (35), (14), (12), (36) \\
\hline At least 24 hours without smoking ever because [respondent was] trying to quit smoking & (14), (37) \\
\hline Intentionally abstained for at least 24 hours in the past 3 months & (38), (39) \\
\hline At least 24 hours without smoking in the past 6 months & (37) \\
\hline Any attempts (undefined) to quit smoking [since previous interview] & (40), (41) \\
\hline 24-hour abstinence & $(42)$ \\
\hline Use of a cessation program or aid & (43), (27), (26), (32), (44) \\
\hline Other or definition not reported (number of quit attempts) & $\begin{array}{l}(45),(17),(13),(46),(47),(48),(49),(50),(51), \\
(16)\end{array}$ \\
\hline Other or definition not reported (number/percent who made a quit attempt) & (20), (46), (47), (50) \\
\hline $\begin{array}{l}\text { Other or definition not reported (time since most recent } \\
\text { quit attempt) }\end{array}$ & $(15)$ \\
\hline \multicolumn{2}{|c|}{$\begin{array}{l}\text { Rate of abstinence/quitting (including but not limited to prolonged abstinence (PA), point prevalence abstinence (PPA), identifiable cigarette type } \\
\text { [menthol versus non-menthol] smoked before quitting, and being a former smoker [versus current smoker]) }\end{array}$} \\
\hline Not smoking at all in past 6 months & (46), (52), (50) \\
\hline Not smoking at all in the past 3 months & (29), (30) \\
\hline Not purchasing a pack in past year & $(53)$ \\
\hline Former smoker vs. current smoker & (54), (55) \\
\hline $\begin{array}{l}\text { Ever-smokers identifying as "non-smoker" or smoking "not at all" or "not currently" at } \\
\text { interview/survey }\end{array}$ & (18), (56), (57), (58), (22), (59), (41) \\
\hline Quit ratio: number of former smokers / number of current plus number of former smokers & $(32)$ \\
\hline Not smoking $\geq 1 \mathrm{CPD}$ in past year & $(55)$ \\
\hline Abstinence over the past 5 years with mean smoking $\leq 1 \mathrm{CPD}$ & $(60)$ \\
\hline Transition from non-established smoking to non-smoking & $(61)$ \\
\hline 7-day PPA & $\begin{array}{l}(62),(45),(27),(63),(26),(64),(65),(47),(23), \\
(24),(66),(48),(49)\end{array}$ \\
\hline 30-day PPA & $(42)$ \\
\hline Salivary cotinine-verified cessation $(\leq 20 \mathrm{ng} / \mathrm{ml}$ ) at week 26 & $(67)$ \\
\hline PA for 30 or more days during the 7 month follow-up period & $(42)$ \\
\hline PA since baseline or quit date & (68), (69), (70), (71) \\
\hline
\end{tabular}




\begin{tabular}{|l|l|}
\hline Measure and definition & Studies \\
\hline Menthol cigarette use prior to quitting & $(54),(46),(50)$ \\
\hline Rate of abstinence/quitting (abstinence definition not reported) & $(43),(56),(72),(73)$ \\
\hline Change in smoking quantity/frequency & $(67),(46),(71)$ \\
\hline Difference/change in CPD & $(18)$ \\
\hline Change from smoking "every day" to smoking "some days" & $(18),(71),(12),(41),(74)$ \\
\hline Retum to smoking/relapse & $(42)$ \\
\hline (Rate of) return to smoking
\end{tabular}

$\mathrm{CPD}=$ cigarettes per day; $\mathrm{ng} / \mathrm{ml}=$ nanograms per milliliter; $\mathrm{PA}=$ prolonged abstinence; $\mathrm{PPA}=$ point (or period) prevalence abstinence

Table 2: Summary of Evidence Related to Duration of Abstinence

\begin{tabular}{|lll} 
Study & Sampling / & Study Findings \\
Recruitment & \\
Strategy ${ }^{2}$ Data & \\
Collection & \\
Period &
\end{tabular}

Decreased Duration of Abstinence with Menthol Cigarette Use

(19) TUS-CPS, Menthol cigarette use was associated with statistically significant lower odds of being a "recent" quitter (those Good $2003,2006 / 2007$ who quit in the past year and had been abstinent for at least 3 months; $\mathrm{AOR}=0.97,95 \% \mathrm{Cl}: 0.96$ to 0.97 ;

$\mathrm{p}<0.001$ ) and a "long-term" quitter (those who quit in the past 5 years and had been abstinent for at least 3 months; AOR=0.94; $95 \% \mathrm{Cl}$ : 0.94 to $0.94 ; \mathrm{p}<0.001)$, compared with use of non-menthol cigarettes.

Further controlling for nicotine dependence resulted in nearly identical odds ratios for being a "recent" quitter $(A O R=0.97,95 \% \mathrm{Cl}: 0.96$ to 0.97; $p<0.001)$ and a "long-term" quitter (AOR=0.95; $95 \% \mathrm{Cl}: 0.95$ to $0.95 ; p<0.001)$. A third adjusted model detected similar odds ratios for "recent" quitters (AOR=0.92, 95\% Cl: 0.91 to 0.92; $\mathrm{p}<0.001)$ and "long-term" quitters $(\mathrm{AOR}=0.95 ; 95 \% \mathrm{Cl}: 0.95$ to $0.95 ; \mathrm{p}<0.001)$.

Results of Mixed Significance for Duration of Abstinence

(20) NHIS-CCS; Increase in Duration of Abstinence with Menthol Cigarette Use

2005 Among the six gender-race/ethnicity interactions, White female former menthol smokers reported statistically significantly longer abstinence than White female former non-menthol smokers (14.8 years vs. 12.5 years, respectively; $\mathrm{p}<0.01)$.

\section{No Difference}

For the other interactions (White males, Black females, Black males, Hispanic females, and Hispanic males), no difference was found.

a Details of sampling and recruitment strategies for the data sources can be found in SUPPLEMENTAL SECTION 9: Study, Data Set, and Sample Characteristics, National Survey Details.

Abbreviations: AOR=adjusted odds ratio; $\mathrm{Cl}=$ confidence interval; NHIS-CCS=National Health Interview Survey Cancer Control Supplement; TUS-CPS=The Tobacco Use Supplement to the Current Population Survey.

Table 3: Summary of Evidence Related to Quit Attempts 
Decreased Quit Attempts with Menthol

(34) TUS-CPS;

$2003,2006 / 2007$

White menthol smokers had statistically significant lower odds of having made a quit attempt in the past year (AOR=0.91, 95\% Cl: 0.84 to $0.99 ; p<0.05$ ).

No Difference in Quits Attempt with Menthol Cigarette Use

(31) Dual frame randomdigit dialing sample;

No difference between menthol and non-menthol smokers in the likelihood of a past-year quit attempt (AOR=1.19, 95\% Cl: 0.97 to1.46; $p=0.92$ ).

October 2012 to July 2013

(37) LYAC; 2011-2012

No difference between menthol and non-menthol smokers in ever having made a quit attempt $(\mathrm{AOR}=0.84$, $95 \% \mathrm{Cl}: 0.43$ to 1.63 ) or having made a quit attempt in the past 6 months (AOR=0.62, 95\% $\mathrm{Cl}: 0.30$ to 1.27).

(40) ITC-4

No difference between smokers who switched from menthol to non-menthol cigarettes compared to smokers who continued smoking menthol cigarettes in quit attempts during (AOR=1.09, 95\% $\mathrm{Cl}$ : 0.78 to

2002-2011 1.52) or after (AOR=1.03, 95\% Cl: 0.66 to 1.60) the switch. Switchers from non-menthol to menthol cigarettes were also no different from smokers who attempted to quit but continued with non-menthol cigarettes during (AOR=1.12, 95\% Cl: 0.80 to 1.57$)$ or after $(A O R=0.91,95 \% \mathrm{Cl}: 0.57$ to 1.44$)$ the switch.

(35) BRFSS subsample No difference between menthol and non-menthol smokers in past year quit attempts $(\mathrm{AOR}=0.96,95 \% \mathrm{Cl}$ : from Florida; April 0.81 to 1.15$)$. 2007

(14) TUS-CPS, 2006-2007

No difference between menthol and non-menthol smokers in the odds of making a quit attempt (AOR=0.98, 95\% Cl: 0.83 to 1.15 )

(20) NHIS-CCS,

No differences between menthol and non-menthol smokers across all six gender-race/ethnicity

2005

(46) COMMIT cessation trial; interactions in predicted past year quit attempts.

No differences between menthol and non-menthol smokers in the odds of having made a quit attempt (AOR=0.91, 95\% Cl: 0.72 to 1.15 ); similarly, no differences were found when analyzing subgroups of Black 1988-1993

(32) NHIS-CCS, No differences between menthol and non-menthol current smokers ( $\mathrm{AOR}=1.05,95 \% \mathrm{Cl}$ : 0.80 to 1.36$)$ or 2005

(36) TUS-CPS; former smokers (AOR=1.29, 95\% Cl: 0.74 to 2.26$)$ in using any type of quit aid.

young adults age 18

No differences between menthol and non-menthol current smokers (AOR=1.00, 95\% Cl: 0.89 to 1.16), current daily smokers (AOR $=1.00,95 \% \mathrm{Cl}$ : 0.85 to 1.18 ), or non-daily smokers (AOR=0.93, $95 \% \mathrm{Cl}$ : 0.62 to to 30; 1.41 ) in the odds of past-year quit attempts. Moreover, no difference was found in the odds of past-year quit attempts between menthol and non-menthol non-daily smokers who reported an intention to quit (AOR=1.35, 95\% Cl: 0.60 to 3.03 ).

2003

Adjusting for various factors in 3 models, results across all models were similar in direction, significance,

(41) CARDIA;

men and women age $18-30$ at baseline;

$1985-2000$ and magnitude and found no difference between menthol and non-menthol smokers in the likelihood of having made a quit attempt in the period preceding each interview (AOR=0.77, $95 \% \mathrm{Cl}$ : 0.56 to 1.06 ; most restrictive model, adjusting for age, race/ethnicity, gender, social factors, and CPD at baseline).

Results of Mixed Significance in Quit Attempts

(30) Probability sampling of stratified clusters of U.S. households;

May/August 2006 to January 2007, and May/August 2010 to January 2011

\section{Increase with Menthol Cigarette Use}

Black menthol, compared to non-menthol, smokers were statistically significantly more likely to report any past-year quit attempts (AOR=1.39, $95 \%$ Cl: 1.16 to $1.67 ; p<0.001)$.

\section{No difference}

No difference between White menthol and non-menthol smokers in the odds of past-year quit attempts (AOR=0.95, 95\% $\mathrm{Cl}: 0.89$ to $1.01 ; p=N S$ ). 


\begin{tabular}{|c|c|c|c|}
\hline Study & $\begin{array}{l}\text { Sampling / } \\
\text { Recruitment } \\
\text { Strategy }{ }^{a} \text {, Data } \\
\text { Collection Period }\end{array}$ & Study Findings & $\begin{array}{l}\text { Study } \\
\text { Quality }\end{array}$ \\
\hline \multirow[t]{5}{*}{$(29)$} & \multirow{2}{*}{$\begin{array}{l}\text { Probability sampling } \\
\text { of stratified clusters } \\
\text { of U.S. households; }\end{array}$} & Increase with Menthol Cigarette Use & \multirow[t]{5}{*}{ Fair } \\
\hline & & $\begin{array}{l}\text { Black menthol smokers were statistically significantly more likely to report past-year quit attempts than } \\
\text { non-menthol smokers (AOR }=1.37,95 \% \mathrm{Cl}: 1.16 \text { to } 1.61 ; \mathrm{p}=0.0002) \text {. }\end{array}$ & \\
\hline & \multirow[t]{3}{*}{$\begin{array}{l}2006 \text { to } 2007 \text { and } \\
2010 \text { to } 2011\end{array}$} & ( & \\
\hline & & $\begin{array}{l}\text { No difference between menthol and non-menthol smokers in past-year quit attempts (AOR=0.99 } 95 \% \mathrm{Cl} \text { : } \\
0.94 \text { to } 1.04 ; p=0.6690) \text {. }\end{array}$ & \\
\hline & & $\begin{array}{l}\text { Similarly, no difference in the odds of past-year quit attempts between: White menthol and non-menthol } \\
\text { smokers }(\mathrm{AOR}=0.97,95 \% \mathrm{Cl}: 0.91 \text { to } 1.02 ; \mathrm{p}=0.2450) ; \text { Asian menthol and non-menthol smokers }(\mathrm{AOR}=0.91 \text {, } \\
95 \% \mathrm{Cl}: 0.62 \text { to } 1.34 ; \mathrm{p}=0.6470) \text {; or Hispanic menthol and non-menthol smokers (AOR=1.09, } 95 \% \mathrm{Cl}: 0.91 \\
\text { to } 1.30 ; \mathrm{p}=0.3540) \text {. }\end{array}$ & \\
\hline \multirow[t]{4}{*}{ (19) } & TUS-CPS; & Increase with Menthol Cigarette Use & \multirow[t]{4}{*}{ Good } \\
\hline & $\begin{array}{l}\text { current smokers and } \\
\text { former smokers who } \\
\text { quit between } 3 \\
\text { months and } 5 \text { years } \\
\text { prior to the survey } \\
\text { interview; }\end{array}$ & $\begin{array}{l}\text { Menthol, versus non-menthol, smokers who were smoking } 1 \text { year prior to the interview had a statistically } \\
\text { significant higher likelihood of past year quit attempts (AOR=1.03, } 95 \% \mathrm{Cl}: 1.02 \text { to } 1.03 ; \mathrm{p}<0.001) \text {. Further } \\
\text { controlling for nicotine dependence resulted in a nearly identical and statistically significant higher } \\
\text { likelihood of a past year quit attempt for menthol, versus non-menthol, smokers who were smoking } 1 \text { year } \\
\text { prior to the interview (AOR=1.02, } 95 \% \mathrm{Cl}: 1.02 \text { to } 1.03 \text {; } p<0.001) \text {. }\end{array}$ & \\
\hline & \multirow{2}{*}{$2003,2006 / 2007$} & Decrease with Menthol Cigarette Use & \\
\hline & & $\begin{array}{l}\text { A third adjusted model reported statistically significant lower odds of past-year quit attempts for menthol, } \\
\text { versus non-menthol, smokers (AOR=0.98, } 95 \% \mathrm{Cl}: 0.98 \text { to 0.98). }\end{array}$ & \\
\hline
\end{tabular}

\footnotetext{
a Details of sampling and recruitment strategies for the data sources can be found in SUPPLEMENTAL SECTION 9: Study, Data Set, and Sample
} Characteristics, National Survey Details.

Abbreviations: AOR=adjusted odds ratio; BRFSS=Behavioral Risk Factor Surveillance System; CARDIA=Coronary Artery Risk Development in Young Adults; $\mathrm{Cl}=$ confidence interval; COMMIT=Community Intervention Trial for Smoking Cessation; ITC-4= International Tobacco Control Four Country Survey; LYAC=Legacy Young Adult Cohort Study; NHIS-CCS=National Health Interview Survey Cancer Control Supplement; TUS-CPS=The Tobacco Use Supplement to the Current Population Survey

\section{Table 4: Summary of Evidence Related to Rate of Abstinence/Quitting}


Decreased Rate of Abstinence/Quitting with Menthol Cigarette Use

(43) New York City Nicotine Patch and Gum

Smoking menthol cigarettes was associated with a $10 \%$ lower prevalence of quitting (PR=0.90, 95\% Cl:

Program; 0.83 to 0.97$)$ after 3 to 6 weeks.

2012

(53) Nielsen Homescan Panel;

Menthol smokers had a statistically significant lower likelihood of quitting compared with non-menthol smokers (HR=0.79, $95 \% \mathrm{Cl}: 0.64$ to 0.99$)$.

January 2004

December 2009

(62) A trial of 166 weightconcerned smokers who smoked at least 10 CPD for at least a year and had at least one prior quit attempt;

2005-2009

(27) KIS-III trial;

community-based clinic sample serving a predominantly Black population;

2007-2010
Menthol smokers were statistically significantly less likely to be abstinent; specifically, non-mentho smokers were 2.4 times more likely to report 7-day PPA Weeks 14 and 26 (Week 14: AOR=2.40, 95\% Cl: 1.04 to 5.55 ; Week $26 \mathrm{AOR}=2.47,95 \% \mathrm{Cl}$ : 1.40 to $5.90 ; \mathrm{p}=0.04$ ).

No Difference in Rate of Abstinence/Quitting with Menthol Cigarette Use

(30) Probability sample of U.S. households;

personal and telephone interviews;

May/August 2006 to January 2007, and May/August 2010 to January 2011

(29) Probability sample of U.S. households; personal and telephone interviews;

2006 to 2007 and 2010 to 2011

(63) Randomized trial of U.S. substance use outpatient treatment program participants receiving smoking cessation treatment; Feb 2010-July 2012

(42) ClearWay Minnesota phone line;

No difference between menthol and non-menthol smokers in the odds of quitting (as assessed by 30 day PPA) (AOR=1.29, 95\% Cl: 0.77 to 2.15$)$.
No difference between Black menthol and non-menthol smokers in the rate of successful cessation $(\geq 3$ months) (AOR=1.01, 95\% Cl: 0.70 to $1.45 ; p=N S)$. Similarly, no difference was found for the rate of successful cessation ( $\geq 3$ months) between White menthol and non-menthol smokers (AOR=0.94, 95\% $\mathrm{Cl}: 0.84$ to 1.07$)$.
No difference between menthol and non-menthol smokers in the odds of cessation ( $\geq 3$ months) ( S

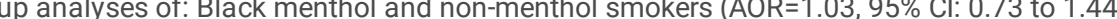
$\mathrm{p}=0.8630$ ); White menthol and non-menthol smokers ( $\mathrm{AOR}=0.94,95 \% \mathrm{Cl}: 0.84$ to $1.06 ; \mathrm{p}=0.3190)$; Asian menthol and non-menthol smokers (AOR=0.98, 95\% Cl: 0.44 to 2.19; $p=0.9540)$; and Hispanic menthol and non-menthol smokers (AOR=0.88, $95 \% \mathrm{Cl}: 0.60$ to $1.28 ; \mathrm{p}=0.4980$

No difference in effect for smoking cessation (as measured by 7-day PPA at week 10) between menthol and non-menthol cigarette type among either the cocaine-dependent $(p=0.81)$ or methamphetaminedependent $(p=0.9)$ participants.

September 2009 July 2011, 7-month post-registration follow-up survey March 2010-February 2011

\section{(61) ALLTURS;}

U.S. school-based survey of middle and high school youth; 2000-2002

(70) Project BREAK FREE Houston metro area; 2005-2007
No difference between those who initiated smoking with menthol and non-menthol in quit rates $(A O R=1.18,95 \% \mathrm{Cl}: 0.78$ to $1.80 ;$ ref=NM).

No difference between menthol and non-menthol cigarette use in predicting prolonged abstinence from

Fair smoking among Black smokers in adjusted analyses $(\beta=.33, S E=.32 ; \chi 2=1.06 ; p=.30 ; n=457)$. 
(69) Project CARE;

Texas;

2005-2007

(64) Cessation study that enrolled 723 smokers age 16-78

(46) COMMIT cessation trial; modified randomdigit-dial method of approximately 5,400 $\mathrm{HHs}$ with focus on communities with the highest prevalence of non-Whites;

No difference between menthol and non-menthol cigarette use in predicting prolonged abstinence from smoking in adjusted analyses $(\beta=0.05, \mathrm{SE}=0.25 ; \chi 2=0.04 ; \mathrm{p}=0.84)$.

No difference between menthol and non-menthol smokers in the odds of abstinence (7-day PPA) at 6 Good months after target quit date (AOR=1.02, $95 \% \mathrm{Cl}$ : 0.66 to 1.58$)$.

No differences in quit rates between menthol and non-menthol smokers who were smoking from 1988 to 2001 and had not attempted to quit (AOR=0.84, 95\% Cl: 0.61 to 1.15), who had attempted to quit (AOR $=1.03,95 \% \mathrm{Cl}: 0.71$ to 1.48 ), or among the corresponding White sub-samples (no quit attempts: AOR $=0.79,95 \% \mathrm{Cl}: 0.56$ to 1.11 ; quit attempts: $A O R=0.96,95 \% \mathrm{Cl}: 0.65$ to 1.41 ).

Also, no difference in quitting between menthol and non-menthol cigarette use in 1988 among: smokers in 1993 (AOR $=1.00,95 \% \mathrm{Cl}: 0.90$ to 1.11); White smokers (AOR=0.94, $95 \% \mathrm{Cl}: 0.83$ to 1.05 ); Black smokers (AOR=1.04, 95\% Cl: 0.73 to 1.47); and Hispanic smokers (AOR=1.22, 95\% $\mathrm{Cl}: 0.80$ to 1.87).

1988-2001

(65) Female prison sample; June 2004-June 2006

(23) VA medical center sample;
No differences between menthol and non-menthol smokers in smoking cessation (as evaluated by 7-day PPA) (Wald chi-square $=1.2 ; p=0.272$; and with interaction of race $X$ menthol: Wald chi-square $=0.1$; $p=0.27$ ).

No difference between menthol and non-menthol smokers in smoking abstinence (as assessed by selfreported 7-day PPA) (AOR=1.31, 95\% Cl: 0.95 to 1.82).
Fair

Good

February-October 2002

(24) KIS trial; cessation program of an innercity health center mostly serving a lowincome Black population;

No difference was found for 7-day PPA at week $26(p=0.93)$ between categorized age $(<50$ versus $\geq 50$ years) and menthol status. Further, among the $<50$ years of age group, no difference between menthol and non-menthol smokers in cessation rates (AOR=2.077, 95\% Cl: 0.944 to 4.569; $p=0.069$ ). Likewise, among those $\geq 50$ years, no difference between menthol and non-menthol cigarette use in abstinence (AOR=1.676; $95 \%$ C1: 0.760 to $3.698 ; p=0.221$ ).

March 2003-June 2004

(66) Convenience sample of patients attempting to quit at a specialist tobacco dependence treatment outpatient clinic; 2001-2006

At the four-week follow up, was no difference between menthol and non-menthol smokers in 7-day PPA (AOR=1.36, 95\% Cl: 1.0 to 1.86 ).

\section{CARDIA;}

men and women in the U.S. age $18-30$ at baseline with followup data through year 19; 1985-2000

(55) Newly diagnosed, nonsurgical cancer patients; 1981-1999

No different between menthol and non-menthol smokers in quit rate (i.e., not currently smoking at any examination) (AOR=0.90, 95\% Cl: 0.68 to 1.19). There was also no difference in quitting between menthol and non-menthol smokers who tried to quit (AOR=1.00,95\% $\mathrm{Cl}: 0.71$ to 1.42$)$. In longitudinal analyses, no difference between menthol and non-menthol smokers in sustained smoking cessation (AOR=0.71, $95 \% \mathrm{Cl}: 0.49$ to $1.02 ; \mathrm{p}=0.06$ ).

In adjusted analyses, no difference was found between menthol and non-menthol cigarette use in continued smoking among Black participants (POR=1.1, $95 \% \mathrm{Cl}: 0.8$ to 1.4 ) and White participants (POR=1.1, 95\% Cl: 1.0 to 1.3 ).

Results of Mixed Significance in Rate of Abstinence/Quitting

(54) NHIS;

\section{Decrease with Menthol Cigarette Use}

2005,2010;

TUS-CPS;

$2010 / 2011$
According to the TUS-CPS data, menthol cigarette use among Black regular and daily smokers was statistically significantly lower for the adjusted odds of abstinence for 1-3 years (regular smokers: AOR=0.87, $95 \% \mathrm{Cl}: 0.80$ to 0.95 ; daily smokers: $A O R=0.89,95 \% \mathrm{Cl}: 0.81$ to 0.98 ).

No Difference

According to the NHIS data, among White participants, there was no difference between menthol regular and daily smokers in the adjusted odds of past-year abstinence (regular smokers: AOR=1.06, 95\% Cl: 0.95 to 1.18 ; daily smokers: $\mathrm{AOR}=1.04,95 \% \mathrm{Cl}$ : 0.82 to 1.33 ).

No difference between White menthol and non-menthol regular and daily smokers in the adjusted odds of abstinence for $1-3$ years (regular smokers: AOR $=0.97,95 \% \mathrm{Cl}: 0.94$ to 1.00 ; daily smokers: AOR=0.98, 95\% Cl: 0.95 to 1.01$)$.

For participants whose race/ethnicity was other than White or Black, no difference for abstinence for 1-3 years between menthol and non-menthol smokers (regular smokers: AOR=0.99, 95\% Cl: 0.91 to 1.08; daily smokers: $\mathrm{AOR}=1.00,95 \% \mathrm{Cl}: 0.92$ to 1.09 ). 
lung cancer casecontrol study;

February 1996-July 2001
(68) Texas;

Decrease with Menthol Cigarette Use

Menthol cigarette use was statistically significantly associated with a lower probability of short-term continuous smoking abstinence among White participants $(\beta=-1.56, S E=0.79 ; \chi 2=3.96 ; p=0.05)$. Racially stratified analyses also found a statistically significant association of menthol cigarette use with 7-day PPA smoking abstinence through post-quit Week 3 among White participants $(\beta=-1.90, \mathrm{SE}=0.82$; $\mathrm{p}=0.02)$.

\section{No difference}

No significant effect of menthol cigarette use status on continuous short-term smoking abstinence $(\beta=-0.31, \mathrm{SE}=0.40 ; \chi 2=0.60 ; p=0.44)$.

Moreover, no difference between Black menthol, versus non-menthol, smokers for short-term continuous smoking abstinence $(\beta=0.54, S E=0.55 ; \chi 2=0.95 ; p=0.33)$; even after racially stratifying analyses, no difference between Black menthol and non-menthol smokers according to 7-day PPA $(\beta=1.00, \mathrm{SE}=0.67$; $\mathrm{p}=0.11)$

\section{Increase with Menthol Cigarette Use}

in southern U.S.

states;

March 2002 -

September 2009

Adjusting for age and other covariates, White menthol, versus non-menthol, cigarette smokers were more likely to have quit smoking prior to study enrollment (AOR=1.55, 95\% $\mathrm{Cl}: 1.41$ to 1.70$)$.

\section{No difference}

No difference between Black menthol and non-menthol cigarette smokers in the likelihood of quitting smoking prior to study enrollment (AOR=1.03, 95\% Cl: 0.96 to 1.11$)$.

(57, TUS-CPS,

58) $\quad 2003,2006 / 2007$
Adjusted odds of being a former smoker (menthol versus non-menthol) was measured across five sample restrictions: cigarette smokers and former smokers who quit in the past 5 years (restriction 1); cigarette smokers and former smokers who quit in the past 5 years who do not currently use other tobacco products (restriction 2); cigarette smokers and former smokers who quit in the past 5 years who have made a quit attempt (restriction 3); cigarette smokers and former smokers who quit in the past 5 years who have made a quit attempt and do not currently use other tobacco products (restriction 4); and past-year smokers (restriction 5, also adjusting for past-year cigarette tax increase).

\section{Decrease with Menthol Cigarette Use}

The odds of being a former smoker were statistically significantly lower among menthol, versus nonmenthol, smokers in the overall sample with the least restrictions (restriction 1; AOR $=0.91,95 \% \mathrm{Cl}: 0.87$ to 0.96 ). The same statistically significant difference was consistently found across restrictions 2,3 , and 4 with AORs ranging from 0.90 to 0.92 .

Black menthol smokers were statistically significantly less likely to be former smokers with restriction 1 (AOR $=0.81,95 \% \mathrm{Cl}: 0.67,0.98)$ and across all four additional sample restrictions with the range of AORs from 0.68 to 0.81 .

White menthol smokers had statistically significant lower odds of being a former smoker (AOR=0.93, $95 \% \mathrm{Cl}: 0.88,0.98)$ across three of the five sample restrictions $(1,2$ and 3$)$.

Puerto Rican menthol smokers were consistently and statistically significantly less likely to be former smokers across all five sample restrictions, with AORs ranging from 0.42 to 0.63 .

\section{Increase with Menthol Cigarette Use}

Two of the five sample restrictions (2 and 4 ) reported statistically significant higher odds of being a former smoker among Mexican menthol, versus non-menthol, smokers with AORs of 1.34 and 1.35, respectively.

\section{No difference}

No difference between menthol and non-menthol smokers was found in the adjusted odds of being a former smoker for the overall sample (AOR $=0.922,95 \% \mathrm{Cl}: 0.847$ to 1.004$)$.

Also, no difference between White menthol and non-menthol smokers in the odds of being a former smoker (restrictions 4 and 5); likewise, no difference between Hispanic menthol and non-menthol smokers (restrictions 1 to 4); and, no difference between Mexican menthol and non-menthol smokers (restrictions 1, 3, and 5). 


\begin{tabular}{|c|c|c|c|}
\hline Study & $\begin{array}{l}\text { Sampling / } \\
\text { Recruitment Strategy } \\
\text { Data Collection Period }\end{array}$ & Study Findings & $\begin{array}{l}\text { Study } \\
\text { Quality }\end{array}$ \\
\hline \multirow{5}{*}{$\begin{array}{l}(71, \\
75)\end{array}$} & Project MOM; & Decrease with Menthol Cigarette Use & Good \\
\hline & $2005-2007$ & $\begin{array}{l}\text { Adjusting for age, partner status, income, and educational achievement, time, treatment group, CPD, and } \\
\text { time to the first cigarette of the day, White female menthol, versus non-menthol, cigarette smokers were } \\
\text { statistically significantly less likely to maintain continuous abstinence }(\beta=-1.62, S E=0.76 ; \chi 2=4.49 \\
p=0.03 ; A O R=0.19,95 \% \mathrm{Cl}: 0.04 \text { to } 0.89) \text {. }\end{array}$ & \\
\hline & & No Difference & \\
\hline & & $\begin{array}{l}\text { Across the entire sample, no difference between menthol and non-menthol use in continuous abstinence } \\
\text { from smoking through } 26 \text { weeks postpartum }(\beta=-0.32, S E=0.30 ; p=0.29 ; n=297) \text {. }\end{array}$ & \\
\hline & & $\begin{array}{l}\text { No difference between Black female menthol and non-menthol smokers in continuous abstinence } \\
(\beta=-1.12, S E=.64 ; c 2=3.06 ; p=.08 ; n=96) ; \text { likewise, no difference between Latina female menthol and } \\
\text { non-menthol smokers in continuous abstinence }(\beta=.46, S E=.50 ; c 2=.86 ; p=.35 ; n=93) \text {. }\end{array}$ & \\
\hline \multirow[t]{4}{*}{$(52)$} & TUS-CPS; & Descrease with Menthol Cigarette Use & Good \\
\hline & $2003,2006-2007$ & 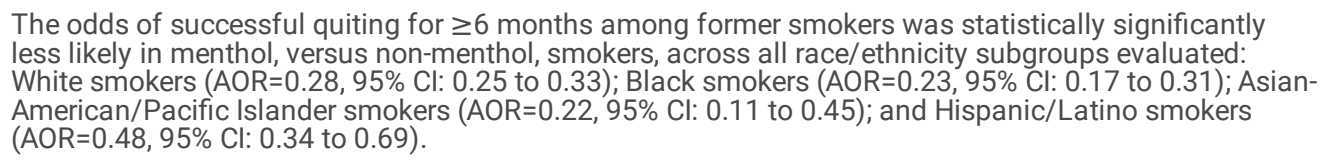 & \\
\hline & & No Difference & \\
\hline & & $\begin{array}{l}\text { No difference between Native American/Alaskan Native former menthol and non-menthol smokers in } \\
\text { the odds of successful quiting for } \geq 6 \text { months (AOR=0.49,95\% Cl: } 0.14 \text { to } 1.71 \text { ). }\end{array}$ & \\
\hline \multirow[t]{5}{*}{ (47) } & \multirow{5}{*}{$\begin{array}{l}\text { Outpatient tobacco } \\
\text { treatment clinic } \\
\text { patients; } \\
\text { January 2001-June } \\
2005\end{array}$} & Decrease with Menthol Cigarette Use & Fair \\
\hline & & $\begin{array}{l}\text { The odds of Black menthol, versus non-menthol, smokers' abstinence were statistically significantly } \\
\text { lower at } 4 \text { weeks (measured by } 7 \text {-day PPA) (AOR=0.32, } 95 \% \mathrm{Cl}: 0.16 \text { to } 0.62) \text { and at } 6 \text { months post-quit } \\
\text { (AOR=0.48, } 95 \% \mathrm{Cl}: 0.25 \text { to } 0.90) \text {. }\end{array}$ & \\
\hline & & $\begin{array}{l}\text { Hispanic menthol, versus non-menthol, smokers' odds of abstinence at } 4 \text { weeks post-quit were also } \\
\text { statistically significantly lower (AOR=0.43,95\% Cl: } 0.1 \text { to } 0.9) \text {. }\end{array}$ & \\
\hline & & $\underline{\text { No Difference }}$ & \\
\hline & & $\begin{array}{l}\text { No difference between White menthol and non-menthol smokers in the likelihood of abstinence at } 4 \\
\text { weeks (AOR=0.96, } 95 \% \mathrm{Cl}: 0.72 \text { to } 1.20 \text { ) or } 6 \text { months post-quit (AOR=1.0, } 95 \% \mathrm{Cl}: 0.8 \text { to } 1.4 \text { ). Also, no } \\
\text { difference between Hispanic menthol and non-menthol smokers in the odds of abstinence at } 6 \text { months } \\
\text { (AOR= } 0.64,95 \% \mathrm{Cl}: 0.2 \text { to } 1.80 \text { ). }\end{array}$ & \\
\hline \multirow[t]{8}{*}{ (59) } & NHIS-CCS; 2005 & Decrease with Menthol Cigarette Use & Good \\
\hline & & $\begin{array}{l}\text { Subgroup analysis found that Hispanic menthol, versus non-menthol, smokers were statistically } \\
\text { significantly less likely to have quit smoking (AOR=0.61,95\% Cl: } 0.39 \text { to } 0.97 ; p=0.04) \text {. }\end{array}$ & \\
\hline & & $\begin{array}{l}\text { When Black and Hispanic smokers were combined (defining a "non-White" subsample), non-White } \\
\text { menthol, versus non-menthol, smokers were statistically significantly less likely to have quit smoking } \\
\text { (AOR=0.55, } 95 \% \mathrm{Cl}: 0.43 \text { to } 0.71 ; p<0.01 \text { ). }\end{array}$ & \\
\hline & & $\underline{\text { Increase with Menthol }}$ & \\
\hline & & $\begin{array}{l}\text { Subgroup analysis found that White menthol, versus non-menthol, smokers were statistically } \\
\text { significantly more likely to have quit smoking (AOR=1.17, } 95 \% \mathrm{Cl}: 1.00 \text { to } 1.36 ; \mathrm{p}<0.05) \text {. }\end{array}$ & \\
\hline & & No difference & \\
\hline & & $\begin{array}{l}\text { Without stratifying for race/ethnicity, no difference between menthol and non-menthol smokers in } \\
\text { smoking cessation (AOR=1.05, } 95 \% \mathrm{Cl}: 0.92 \text { to } 1.21) \text {. }\end{array}$ & \\
\hline & & $\begin{array}{l}\text { Subgroup analysis: no difference between Black menthol and non-menthol smokers in the odds of } \\
\text { smoking cessation (AOR=0.78, } 95 \% \mathrm{Cl}: 0.56 \text { to } 1.09) \text {. }\end{array}$ & \\
\hline \multirow[t]{5}{*}{ (49) } & KIS trial; & Decrease with Menthol Cigarette Use & Good \\
\hline & $\begin{array}{l}\text { August } 2000- \\
\text { November } 2000 \text {. }\end{array}$ & $\begin{array}{l}\text { Although biochemically verified 7-day PPA abstinence was measured at both six weeks and six months, } \\
\text { authors only modeled for six weeks "because univariate analysis did not reveal significant differences in } \\
\text { abstinence rates between menthol and non-menthol smokers at } 6 \text { months." In addition, overall modeled } \\
\text { results were not presented. }\end{array}$ & \\
\hline & & $\begin{array}{l}\text { Among adults }<50 \text { years of age, non-menthol, versus menthol, smokers had statistically significantly } \\
\text { higher odds of quitting (AOR=2.02, } 95 \% \mathrm{Cl}: 1.03 \text { to } 3.95) \text {. }\end{array}$ & \\
\hline & & No Difference & \\
\hline & & No difference between menthol and non-menthol smokers $>50$ years of age in abstinence rates $(p=0.57)$. & \\
\hline
\end{tabular}


a Details of sampling and recruitment strategies for the data sources can be found in SUPPLEMENTAL SECTION 9: Study, Data Set, and Sample Characteristics, National Survey Details.

Abbreviations: $\mathrm{AOR}=$ adjusted odds ratio; $\mathrm{Cl}=$ confidence interval; $\mathrm{CPD}=$ cigarettes per day; $\mathrm{HR}=$ hazard ratio; KIS=Kick it at Swope; $\mathrm{NHIS=National} \mathrm{Health}$ Interview Survey; POR=prevalence odds ratio; PPA=point (or period) prevalence abstinence; $\mathrm{SE}=$ standard error; PR=prevalence ratio; TUS-CPS=The Tobacco Use Supplement to the Current Population Survey; WSHS=Wisconsin Smokers Health Study

Table 5: Summary of Evidence Related to Change in Smoking Quantity/Frequency

Study Sampling / Study Findings

Recruitment

Strategya,

Data

Collection

Period

No Difference in Change in Smoking Quantity/Frequency with Menthol Cigarette Use

(50); COMMIT; $\quad$ No difference between menthol and non-menthol smokers in the odds of reducing daily cigarette use over 3 years $\quad$ Good

(46) $\quad$ (AOR=0.83, 95\% Cl: 0.64 to 1.07); subgroup analyses of Black and White smokers also found no difference.
1988-2001 sample ( $\beta$-coefficient $=0.11,95 \% \mathrm{Cl}$ : -0.38 to 0.60$)$, nor in Black, White, or Hispanic subgroups.

Results with Mixed Significance in Smoking Quantity/Frequency

(71, Project MOM; Decrease with Menthol Cigarette Use

75) 2005-2007

Black female menthol, versus non-menthol, smokers reported substantially less cigarette reduction (measured by CPD) over the course of 26 weeks $(\beta=3.82, S E=3.77 ; p=0.02 ; n=71)$.

\section{No Difference}

No difference among female menthol and non-menthol smokers, overall, in changes in smoking frequency over the 26-week period ( $\beta=-0.38, S E=1.15 ; t=-.33 ; p=.74 ; n=222)$.

a Details of sampling and recruitment strategies for the data sources can be found in SUPPLEMENTAL SECTION 9: Study, Data Set, and Sample

Characteristics, National Survey Details.

Abbreviations: AOR=adjusted odds ratio; COMMIT=Community Intervention Trial for Smoking Cessation; $\mathrm{Cl=confidence} \mathrm{interval;} \mathrm{SE}=$ standard error

Table 6: Summary of Evidence Related to Return to Smoking/Relapse

\begin{tabular}{|c|c|c|c|}
\hline Study & $\begin{array}{l}\text { Sampling / } \\
\text { Recruitment } \\
\text { Strategy }{ }^{\text {, Data }} \\
\text { Collection Period }\end{array}$ & Study Findings & $\begin{array}{l}\text { Study } \\
\text { Quality }\end{array}$ \\
\hline \multicolumn{4}{|c|}{ Increased Return to Smoking/Relapse with Menthol Cigarette Use } \\
\hline$(74)$ & $\begin{array}{l}\text { Sample was } \\
\text { recruited from the } \\
\text { Washington DC } \\
\text { metropolitan } \\
\text { area through } \\
\text { flyers, word of } \\
\text { mouth, and online } \\
\text { advertisements }\end{array}$ & $\begin{array}{l}\text { According to logistic regression model results, menthol cigarette use was statistically significantly } \\
\text { associated with greater lapse risk }(A O R=3.474, p<0.05) \text {. Similarly, menthol, versus non-menthol, use was } \\
\text { statistically significantly higher for risk of lapsing within the first } 48 \text { hours of abstinence }(H R=2.798 \text {, Wald } \\
\text { statistic=2.79; } p=0.048) \text {. }\end{array}$ & Good \\
\hline$(41)$ & $\begin{array}{l}\text { CARDIA; } \\
\text { 1985-2000 }\end{array}$ & $\begin{array}{l}\text { The odds of returning to smoking post-cessation were statistically significantly higher for menthol, versus } \\
\text { non-menthol, smokers }(A O R=1.89,95 \% \mathrm{Cl}: 1.17 \text { to } 3.05 ; p=0.009) \text {. }\end{array}$ & Good \\
\hline
\end{tabular}

a Details of sampling and recruitment strategies for the larger and/or national surveys can be found in SUPPLEMENTAL SECTION 9: Study, Data Set, and Sample Characteristics, National Survey Details.

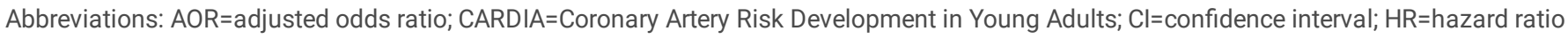

Table 7a: Strength of Evidence Assessment by Measure 


\begin{tabular}{|c|c|c|c|c|c|c|}
\hline & Study limitations & Directness & Consistency & Precision & SOE & CQ assessment \\
\hline \multicolumn{7}{|c|}{ Duration of abstinence } \\
\hline ADJUSTED & Low & Direct & Inconsistent & Precise & Low & Acceptable \\
\hline UNADJUSTED & Medium & Direct & Consistent & Imprecise & Low & Acceptable \\
\hline \multicolumn{7}{|l|}{ Quit Attempts } \\
\hline ADJUSTED & Low & Indirect & Inconsistent & Imprecise & Insufficient & Acceptable \\
\hline UNADJUSTED & Medium & Indirect & Inconsistent & Imprecise & Insufficient & Acceptable \\
\hline \multicolumn{7}{|c|}{ Rate of abstinence/quitting } \\
\hline ADJUSTED & Low & Direct & Inconsistent & Imprecise & Moderate & Acceptable \\
\hline UNADJUSTED & Medium & Direct & Consistent & Imprecise & Low & Acceptable \\
\hline \multicolumn{7}{|c|}{ Change in quantity/frequency } \\
\hline ADJUSTED & Low & Indirect & Consistent & Imprecise & Insufficient & Acceptable \\
\hline UNADJUSTED & Low & Indirect & Inconsistent & Imprecise & Insufficient & Acceptable \\
\hline \multicolumn{7}{|c|}{ Return to smoking/relapse } \\
\hline ADJUSTED & Low & Direct & Inconsistent & Imprecise & Insufficient & Inconclusive \\
\hline UNADJUSTED & Medium & Direct & Unknown* & Imprecise & Insufficient & Inconclusive \\
\hline
\end{tabular}

$\mathrm{CQ}=$ = Contextual Question; SOE = Strength of Evidence; NA = Not Applicable

Table 7b: Overall Strength of Evidence Assessment

\begin{tabular}{|c|c|c|c|}
\hline Measure Name & CQ Assessment & Measure SOE & Overall SOE \\
\hline \multicolumn{4}{|l|}{ Adjusted Analyses } \\
\hline Duration of abstinence & Acceptable & Low & \multirow[t]{5}{*}{ Low } \\
\hline Quit attempts & Acceptable & Insufficient & \\
\hline Rate of abstinence/quitting & Acceptable & Moderate & \\
\hline Change quantity/frequency & Acceptable & Insufficient & \\
\hline Return to smoking/relapse & Inconclusive & Insufficient & \\
\hline \multicolumn{4}{|l|}{ Unadjusted Analyses } \\
\hline Duration of abstinence & Acceptable & Low & \multirow[t]{5}{*}{ Low } \\
\hline Quit attempts & Acceptable & Insufficient & \\
\hline Rate of abstinence/quitting & Acceptable & Low & \\
\hline Change quantity/frequency & Acceptable & Insufficient & \\
\hline Return to smoking/relapse & Inconclusive & Insufficient & \\
\hline
\end{tabular}

$\mathrm{CQ}=$ Contextual Question; SOE = Strength of Evidence

\section{Figures}




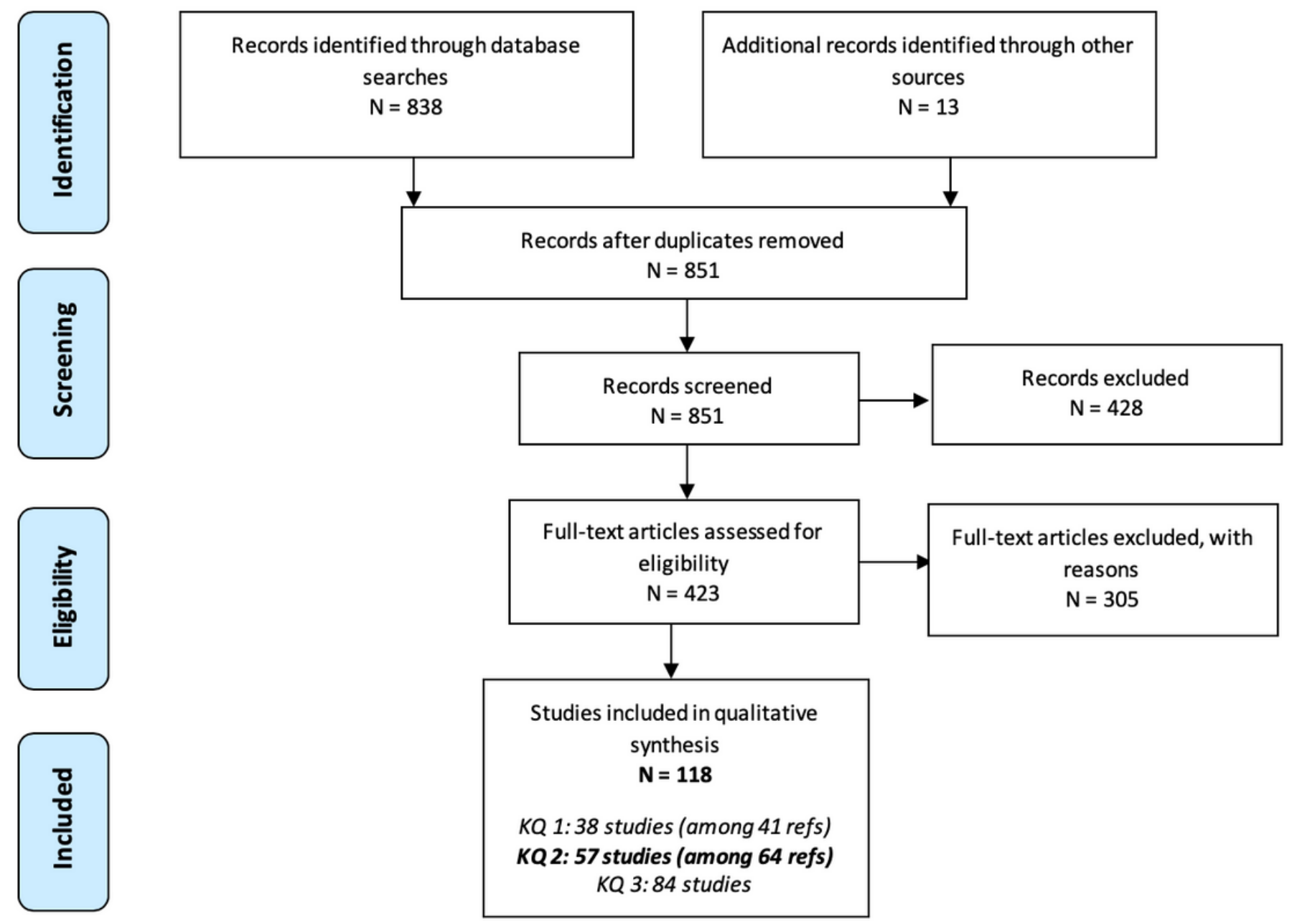

Figure 1

Literature Search Overview

\section{Supplementary Files}

This is a list of supplementary files associated with this preprint. Click to download.

- ISSMPRISMAChecklist.pdf

- KQ2mentholHarmReductionJournalSUPPSFINALJAN202020.docx 